\title{
The Effects of Exercise Training on Obesity-Induced Dysregulated Expression of Adipokines in White Adipose Tissue
}

\author{
Takuya Sakurai, ${ }^{1}$ Junetsu Ogasawara, ${ }^{1}$ Takako Kizaki, ${ }^{1}$ \\ Shogo Sato, ${ }^{1}$ Yoshinaga Ishibashi, ${ }^{1}$ Motoko Takahashi, ${ }^{2}$ Osamu Kobayashi, ${ }^{3}$ Shuji Oh-ishi, ${ }^{4}$ \\ Junichi Nagasawa, ${ }^{5}$ Kazuto Takahashi, ${ }^{6}$ Hitoshi Ishida, ${ }^{6}$ Tetsuya Izawa, ${ }^{7}$ and Hideki Ohno ${ }^{1}$ \\ ${ }^{1}$ Department of Molecular Predictive Medicine and Sport Science, Kyorin University, School of Medicine, 6-20-2 Shinkawa, \\ Mitaka, Tokyo 181-8611, Japan \\ ${ }^{2}$ Department of Biochemistry, Sapporo Medical University School of Medicine, South-1 West-17, Chuo-ku, Sapporo, \\ Hokkaido 060-8556, Japan \\ ${ }^{3}$ Department of Nursing, Kyorin University, Faculty of Health Science, 6-20-2 Shinkawa, Mitaka, Tokyo 181-8611, Japan \\ ${ }^{4}$ Department of Respiratory Medicine, Hachioji Medical Center, Tokyo Medical University, 1163 Tatemachi, Hachioji, \\ Tokyo 193-0998, Japan \\ ${ }^{5}$ Department of Applied Physics and Chemistry, The University of Electro-Communications, 1-5-1 Chofugaoka, Chofu, \\ Tokyo 182-8585, Japan \\ ${ }^{6}$ Third Department of Internal Medicine, Kyorin University, School of Medicine, 6-20-2 Shinkawa, Mitaka, Tokyo 181-8611, Japan \\ ${ }^{7}$ Department of Sports Biochemistry, Faculty of Health and Sport Science, Doshisha University, 1-3 Tatara Miyakodani, \\ Kyotanabe, Kyoto 610-0394, Japan
}

Correspondence should be addressed to Takuya Sakurai; sakutaku@ks.kyorin-u.ac.jp

Received 6 July 2013; Revised 7 October 2013; Accepted 10 October 2013

Academic Editor: Eun Seok Kang

Copyright (C) 2013 Takuya Sakurai et al. This is an open access article distributed under the Creative Commons Attribution License, which permits unrestricted use, distribution, and reproduction in any medium, provided the original work is properly cited.

\begin{abstract}
Obesity is recognized as a risk factor for lifestyle-related diseases such as type 2 diabetes and cardiovascular disease. White adipose tissue (WAT) is not only a static storage site for energy; it is also a dynamic tissue that is actively involved in metabolic reactions and produces humoral factors, such as leptin and adiponectin, which are collectively referred to as adipokines. Additionally, because there is much evidence that obesity-induced inflammatory changes in WAT, which is caused by dysregulated expression of inflammation-related adipokines involving tumor necrosis factor- $\alpha$ and monocyte chemoattractant protein 1 , contribute to the development of insulin resistance, WAT has attracted special attention as an organ that causes diabetes and other lifestylerelated diseases. Exercise training (TR) not only leads to a decrease in WAT mass but also attenuates obesity-induced dysregulated expression of the inflammation-related adipokines in WAT. Therefore, TR is widely used as a tool for preventing and improving lifestyle-related diseases. This review outlines the impact of TR on the expression and secretory response of adipokines in WAT.
\end{abstract}

\section{Introduction}

In recent years, obesity caused by the hypertrophy of white adipose tissue (WAT) has steadily increased worldwide, and has become a serious social problem [1]. In 2010, the Organization for Economic Cooperation and Development (OECD) released a report on the current state of obesity and the costeffectiveness of preventive measures [2,3]. That report states that obesity rates have risen in many countries, and that one in two individuals is either obese or overweight in about half of OECD countries. It is widely known that obesity is a risk factor for various "lifestyle-related diseases" such as type 2 diabetes and hypertension, and that obesity and diabetes cause increases in atherosclerotic disease. Therefore, there is an urgent need to establish strategies for the prevention and improvement of obesity and diabetes.

Epidemiological studies have shown that exercise is effective for preventing and improving obesity and diabetes 
$[4,5]$. For example, a study by Helmrich et al. [6] followed 5,990 male graduates of the University of Pennsylvania over 14 years and found that the risk of developing diabetes is reduced by $6 \%$ for every $500 \mathrm{kcal}$ increase in weekly exercise. Furthermore, a study that followed 21,271 male U.S. doctors over five years revealed that even a once-weekly bout of exercise at an intensity that is sufficient to cause sweating reduced the risk of developing diabetes [7]. In addition, results from a study that followed 87,253 female U.S. nurses over eight years showed that the group that exercised at least once a week at an intensity sufficient to cause sweating had a relative risk of developing diabetes of 0.84 compared with a group that exercised less than once a week [8].

Although WAT was once considered to be merely a site for energy storage, in recent years it has become better understood at the molecular level; for example, how WAT secretes physiologically active substances, collectively known as adipokines, and how obesity-induced dysregulated expression of adipokines in WAT causes insulin resistance, which is the pathogenesis of diabetes [9-11]. Therefore, WAT is considered to be one of the tissues that play a critical role in the onset of lifestyle-related diseases, and the reduction of excess WAT and the improvement of abnormal adipokine secretion are important strategies for the prevention and improvement of lifestyle-related diseases. Exercise training (TR) not only causes a loss of WAT mass, but can also influence the secretory response and expression of adipokines in WAT. This review outlines the impact of TR on the adipokines in WAT.

\section{Adipokines and the Inflammatory Response of WAT}

The major role of subcutaneous and visceral WAT is to supply and store energy via adipocytes in WAT. Most of the ingested excess energy is stored within adipocytes in the form of triglycerides, which are formed through the binding of glycerol and fatty acids. During exercise, catchecolamines (adrenaline and noradrenaline) secreted from the adrenal medulla or the sympathetic nerve terminal break down triglycerides within adipocytes, and the resultant fatty acids are carried to skeletal muscle via the blood [12]. However, following the discovery of leptin by Zhang et al. [13] in 1994, leptin was established as a hormone that is secreted by WAT, and a string of new humoral factors that are secreted by WAT were discovered. Therefore, the old concept of WAT as a mere storage site for energy has been revised to also acknowledge it as an endocrine organ. The humoral factors secreted from WAT are collectively referred to as adipokines (Figure 1).

In recent years, it has become clear that obesity is a chronic and mild systemic inflammatory condition, and there is much evidence that chronic inflammation of WAT contributes to the development of insulin resistance. This systemic inflammation has become closely acknowledged as the molecular basis of diabetes [9-11]. When adipocyte hypertrophy occurs due to excessive energy intake or lack of exercise, infiltration by macrophages, which are one type of immunocompetent cell, is observed in WAT. In

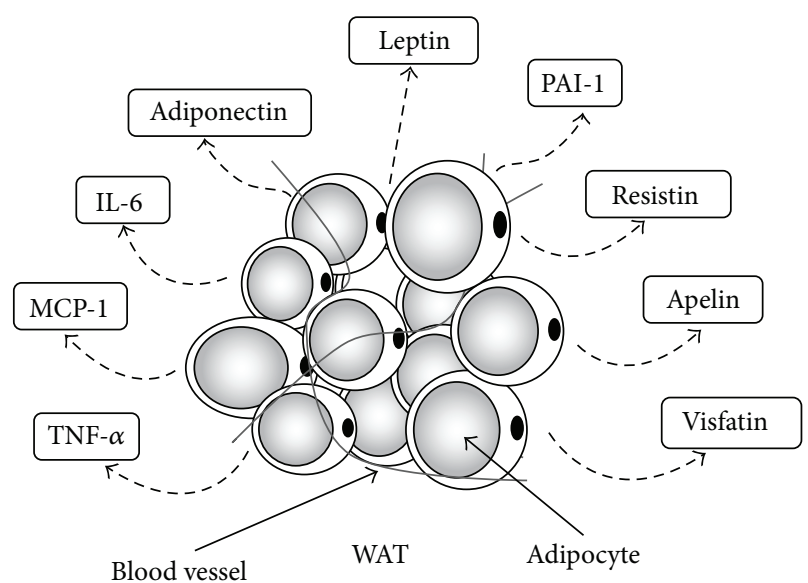

FIgURE 1: Adipokines secreted by white adipose tissue. White adipose tissue (WAT) secretes various humoral factors called adipokines. Adipokines have important effects on lipid and glucose metabolism, and so on. TNF- $\alpha$, tumor necrosis factor- $\alpha$; MCP1, monocyte chemoattractant protein-1; IL-6, interleukin-6; PAI-1, plasminogen activator inhibitor-1.

WAT infiltrated by macrophages, the production of proinflammatory adipokines, such as tumor necrosis factor- $\alpha$ (TNF- $\alpha$ ) and monocyte chemoattractant protein 1 (MCP1 ), is increased and the production of anti-inflammatory adiponectin is decreased, thereby causing chronic inflammation of WAT (Figure 2) [14-16]. This increase in proinflammatory adipokines is not limited to WAT, but also promotes insulin resistance in skeletal muscle and liver as a paracrine agent. Thus, the inflammatory response plays an important role in WAT activity.

\section{Representative Adipokines and the Effects of TR}

3.1. Leptin. Leptin is a hormone that acts on leptin receptors (ob-R) in the hypothalamus to strongly suppress appetite and promote increased energy expenditure [17-19]. There is strong ob-R expression in the arcuate nucleus, ventromedial hypothalamic nucleus, dorsomedial hypothalamic nucleus, and lateral hypothalamic area of the hypothalamus [18]. Although the expression of mRNA for leptin is elevated in the WAT of obese humans and animals and blood levels also increase, since there is impaired leptin action called "leptin resistance", leptin does not function sufficiently to suppress appetite or promote energy expenditure [18, 20-22]. On the other hand, it is also known that leptin has inflammatory effects, such as increasing the expression of inflammatory cytokines involving TNF- $\alpha$ by acting on monocytes [9].

Evidence shows that seven weeks of spontaneous running TR reduces the expression of mRNA for leptin in the visceral and subcutaneous WAT of obese rats (Table 1) [23]. Additionally, other research indicates that even a short duration (four weeks) of spontaneous activity reduces leptin mRNA expression in rat WAT (Table 1) [24]. For obese humans, however, one study found that even 12 weeks of one-hour aerobic 


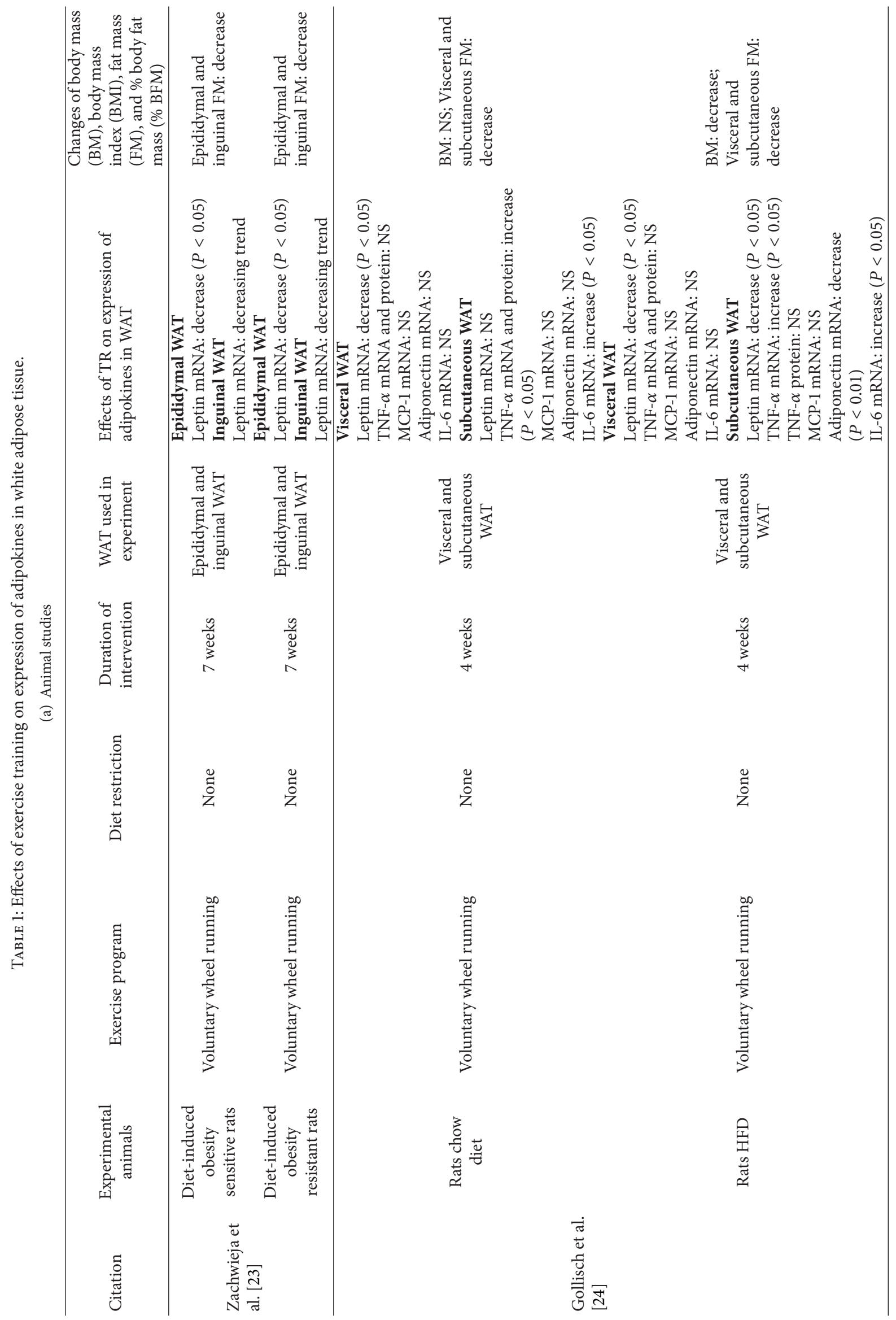




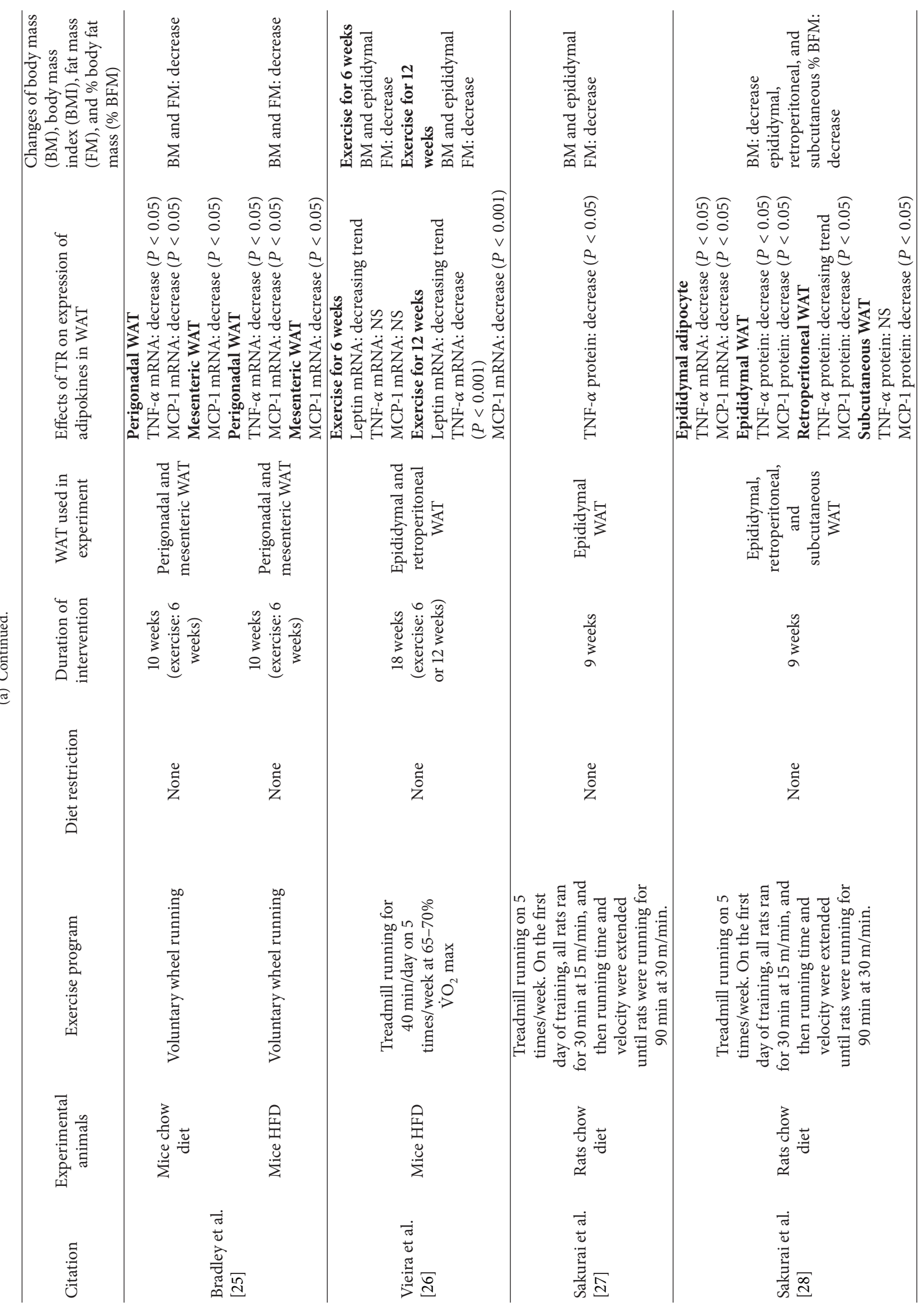




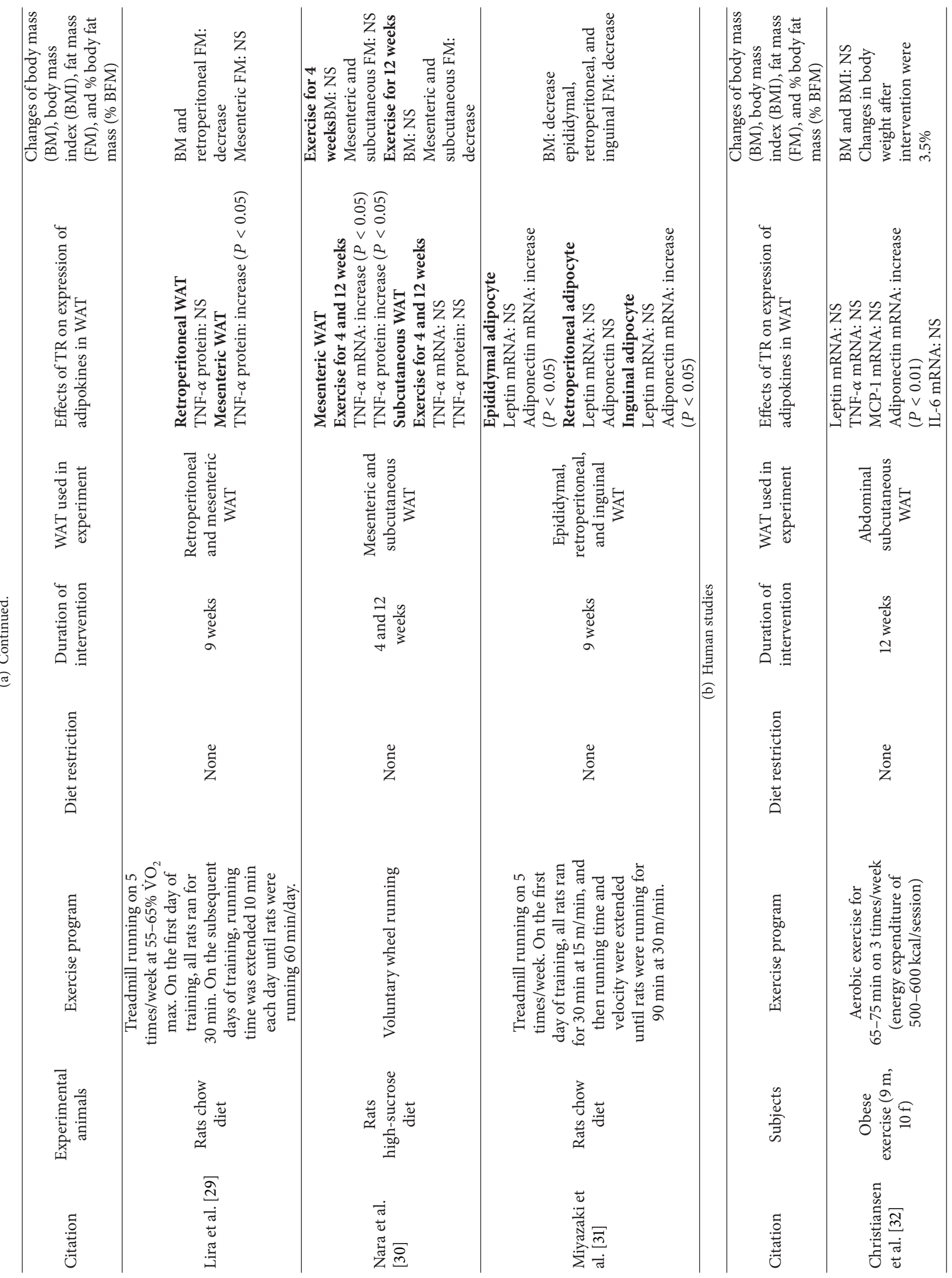




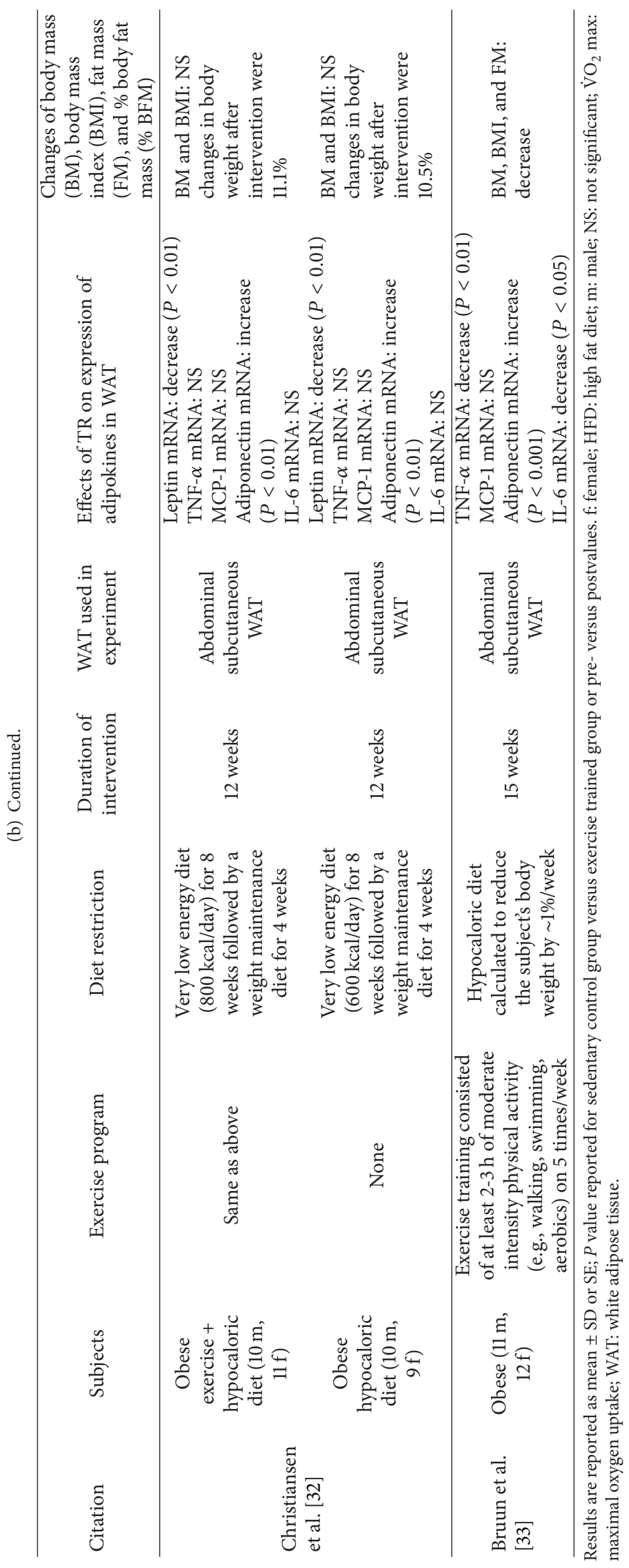




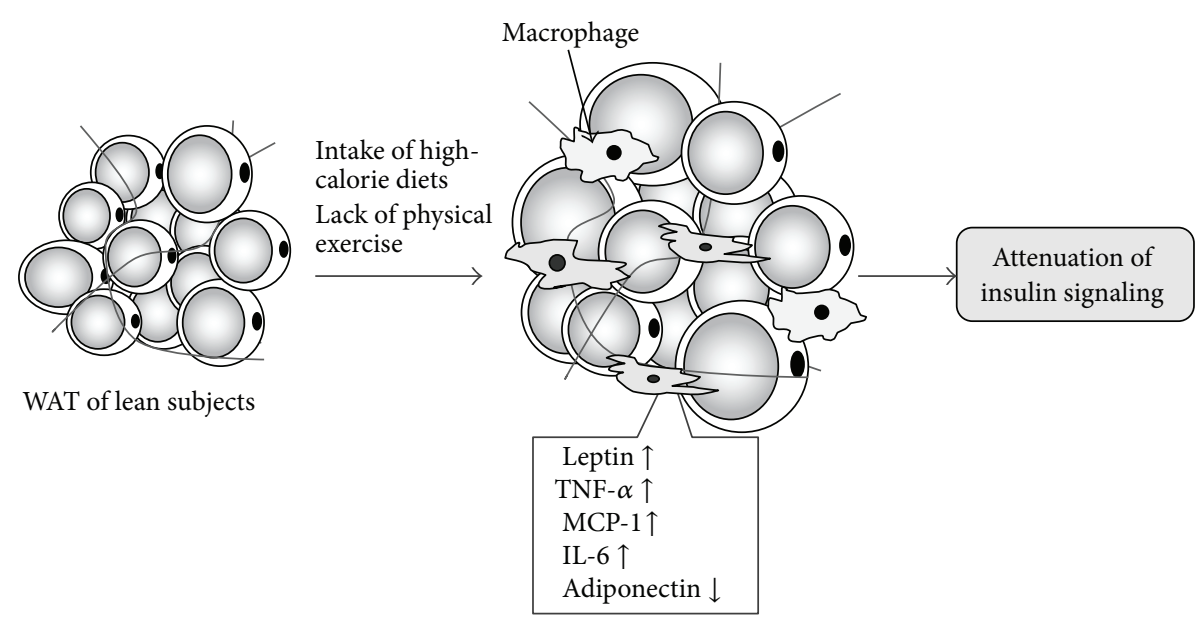

WAT of obese subjects

FIGURE 2: Model of the development of chronic inflammation in WAT. Adipocytes begin to grow as a result of factors such as excess energy intake and lack of exercise, and MCP-1 is secreted from these enlarged adipocytes. Macrophages infiltrate into WAT by the action of MCP-1, and as a result, increased expression of inflammatory adipokines (TNF- $\alpha$, MCP-1, and IL- 6 ) and decreased expression of antiinflammatory adipokines (adiponectin) occur in WAT. Dysregulated expression of adipokines-induced inflammation of WAT contributes to the development of insulin resistance.

exercise sessions had no effect on the expression of mRNA for leptin in subcutaneous WAT (Table 1) [32]. On the other hand, there have been many studies on the effects of TR on the human blood levels of leptin (Table 2) [34-50]. Many cases have shown that concentrations of leptin decrease a reduction in WAT mass (Table 2) [34, 36, 41-45, 47, 48]. By contrast, when no significant differences are observed in blood leptin levels after TR, neither is body fat reduced (Table 2) [34, 35, 39]. Therefore, the reduced blood concentration of leptin after TR is due more to the reduction in body fat caused by TR than to the effects of TR itself. Some studies, however, suggest that a longer duration ( $\geq 12$ weeks) of TR or TR with caloric restriction can contribute to a reduction in blood leptin concentration that is independent of the influence of body fat reduction (Table 2) [34, 37, 40, 46].

Several studies have also concentrated on the effects of resistance training, such as the bench press exercise, on blood leptin levels (Table 2). One study on postmenopausal obese women found that after performing three days a week of resistance training using machines and restricting diet for 16 weeks, blood leptin levels were decreased compared with pretraining levels, but that resistance training alone had no effect on leptin [49]. However, when elderly individuals were divided into low intensity $(45-50 \% 1$ repetition maximum $[\mathrm{RM}])$, moderate intensity (60-65\% 1 RM), and high intensity (80-85\% 1 RM) groups and performed 60-minute exercise sessions three times a week for six months, blood leptin levels were lower in all the groups compared with the respective pretraining levels, and the magnitude of this decrease was significantly greater in the high intensity group than in the low and moderate intensity groups [50]. Furthermore, although blood leptin levels were higher at six months after the end of training than immediately after the end of training, the levels remained significantly lower than their pretraining values in the high intensity group [50].

3.2. $T N F-\alpha$. Since the discovery that gene expression of the major inflammatory cytokine TNF- $\alpha$ is elevated in WAT in animal models of obesity, there have been many studies on its involvement in insulin resistance and its other actions $[51,52]$. Expression of TNF- $\alpha$ increases not only in the WAT of obese animals, but also in that of obese humans; that is, TNF- $\alpha$ has a strong positive correlation with body mass index (BMI) and blood insulin levels [53-55]. TNF- $\alpha$ weakens insulin signaling by insulin receptor substrate 1-mediated inhibition of insulin receptor tyrosine kinase activity in areas such as skeletal muscle and causes reduced expression of glucose transporters and adiponectin in adipocytes, which contributes to the development of insulin resistance [56-58].

There is no clear consensus regarding the effects of TR on TNF- $\alpha$ in WAT (Table 1). For example, increased expression of TNF- $\alpha$ in visceral WAT in mice that became obese after six weeks of consuming a high-fat diet can be suppressed by spontaneous running $[25,26]$. Additionally, our studies showed that nine weeks of treadmill running decreased the TNF- $\alpha$ protein content of the rat WAT $[27,28]$, but some results have shown a contrasting increase after TR $[24,29,30]$. Studies regarding obese individuals have also examined the effects of TR on TNF- $\alpha$ expression in WAT. Although one study found that TNF- $\alpha$ expression in the subcutaneous WAT of severely obese male and female adults decreased after 15 weeks of performing TR, such as walking for five days a week and undergoing diet therapy; a conflicting study on obese adults found that there was no change in TNF- $\alpha$ mRNA expression in subcutaneous WAT even when weight or body fat decreased after 12 weeks of aerobic exercise [32, 33]. 


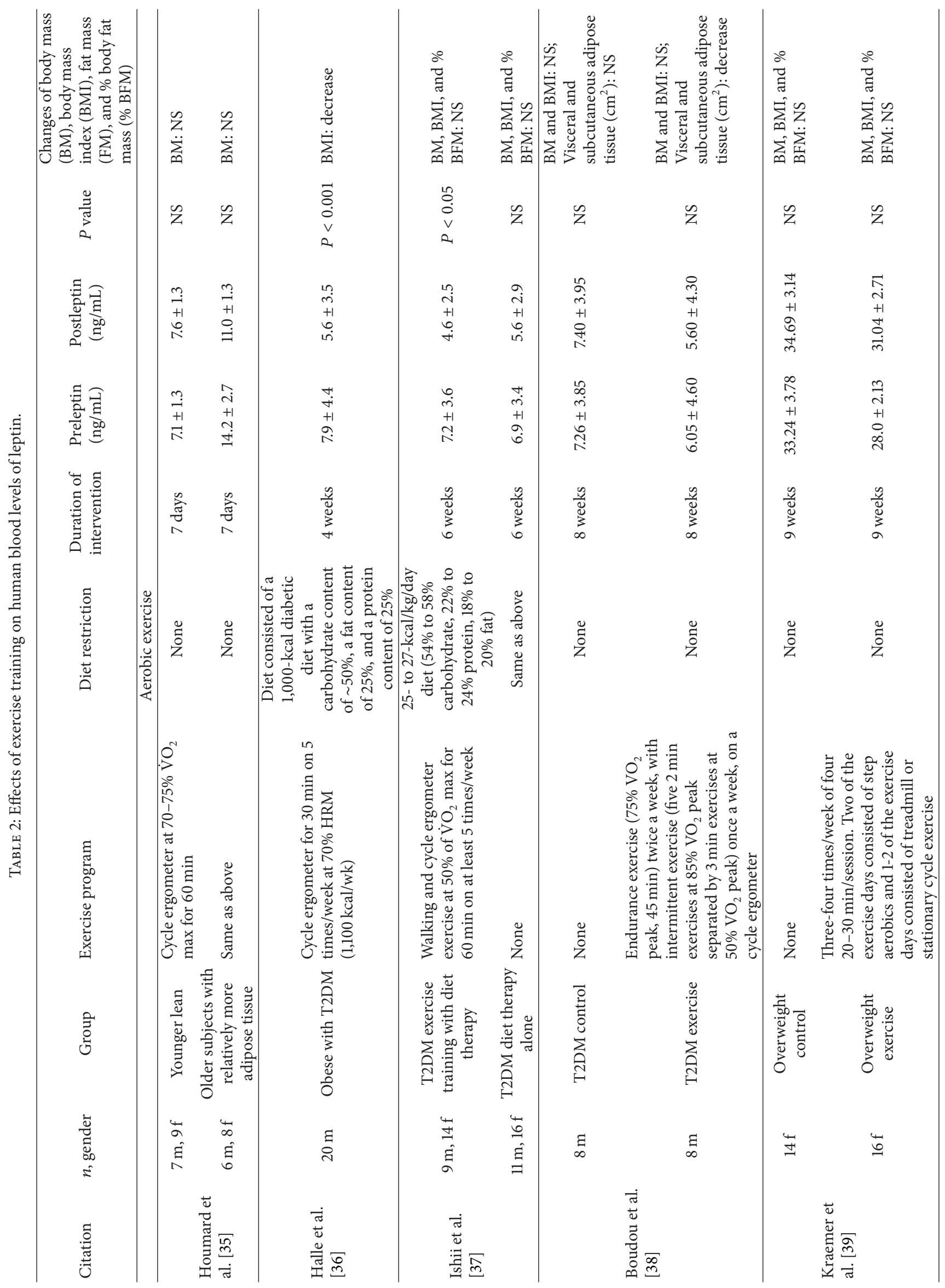




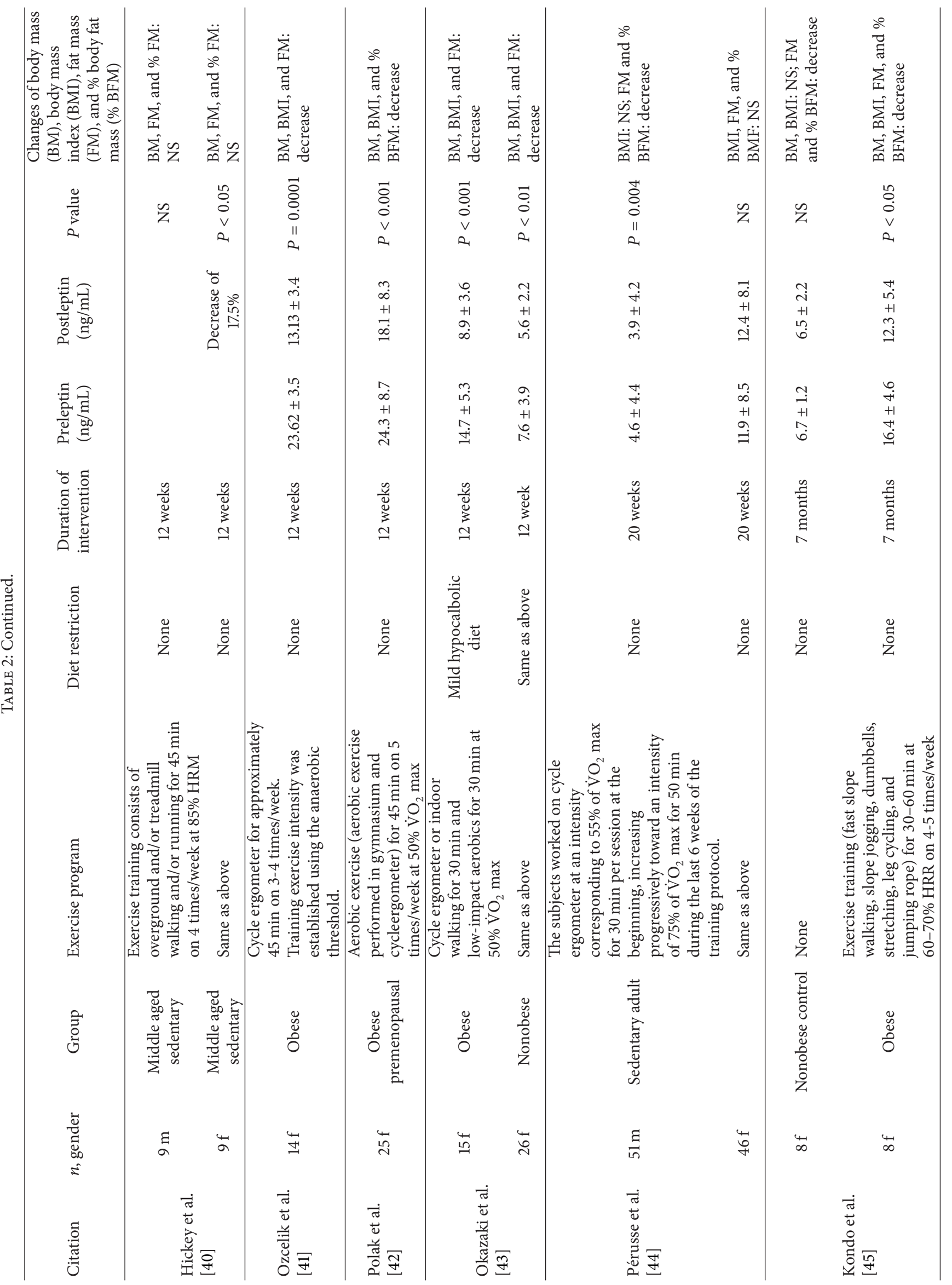






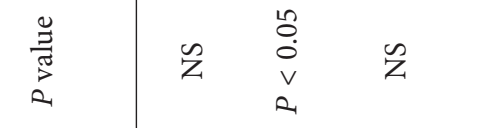

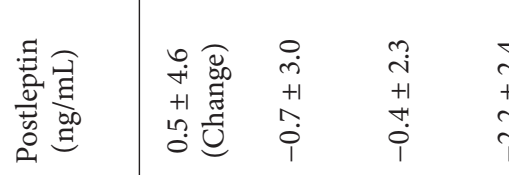

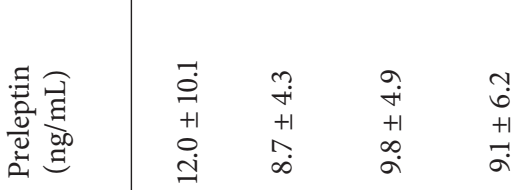

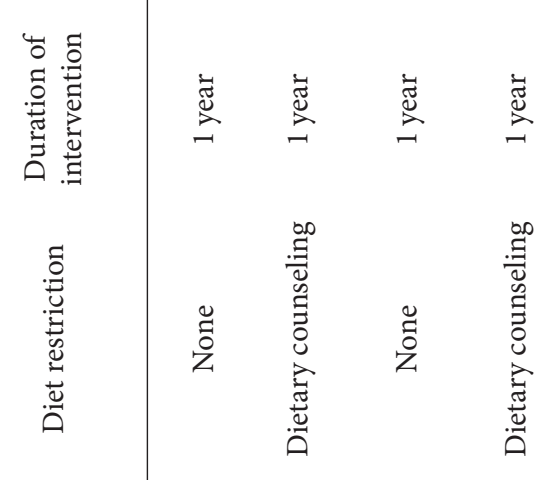

递

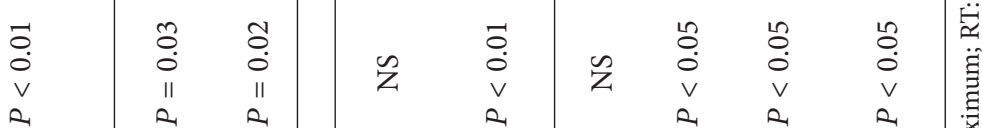

$\left.\begin{array}{llllllllll}a & a\end{array}\right]$

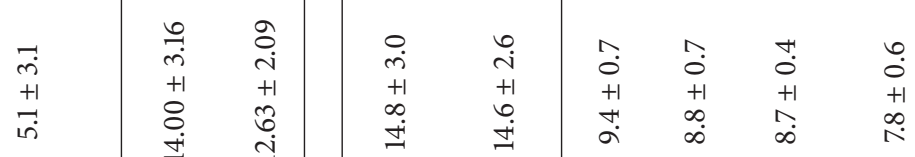

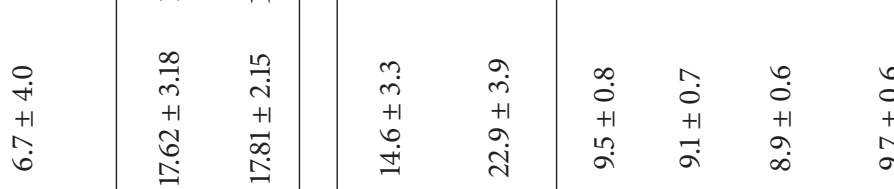

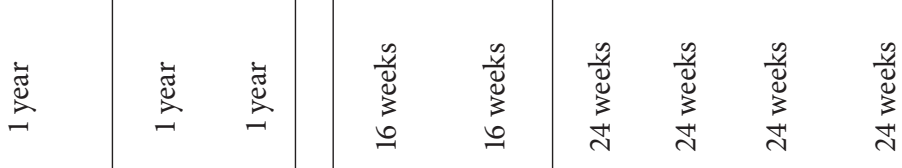

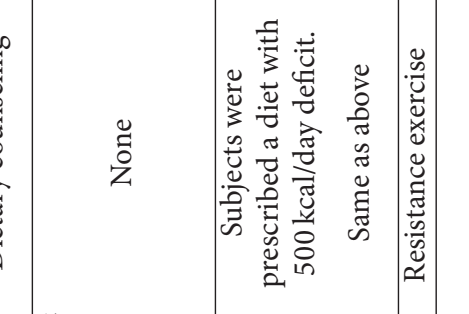

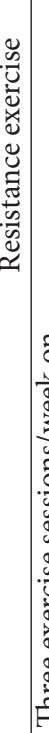

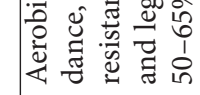

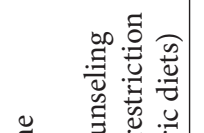

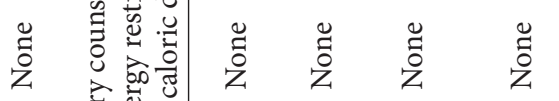

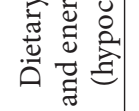


There are also conflicting results for the blood concentrations of TNF- $\alpha$ (Table 3) [33, 42, 45, 59-63]. A study on diabetic patients showed that although there is no change in blood TNF- $\alpha$ concentration after four weeks of dietary restrictions and walking TR in nonobese diabetic patients, the concentration decreased in obese patients [59]. Furthermore, when obese adult women exercised on a bicycle ergometer for 30 minutes a day, five days a week at $70 \% \dot{\mathrm{VO}}_{2} \max$ for 12 weeks, decreases in blood concentrations of both TNF- $\alpha$ and soluble TNF receptor 2 were observed in both the women with insulin resistance and those without [60]. In another study, however, a 15-week combination of diet therapy and TR did not affect the TNF- $\alpha$ level in obese individuals [33]. In yet another study, 12 weeks of endurance TR actually increased the blood concentration of TNF- $\alpha$ in adult women [61].

3.3. MCP-1. MCP-1, which is identified as a monocyte chemotactic factor, shows increased expression in the WAT of obese mice, and elevated MCP-1 contributes to inflammatory changes by inducing macrophage infiltration into WAT via its receptor, $\mathrm{C}-\mathrm{C}$ chemokine receptor-2, which is expressed in monocytes and macrophages [70, 71]. In mice that are genetically modified to only express MCP-1 excessively in adipocytes, infiltration into visceral WAT by macrophages is elevated when compared with control mice, and there is increased expression of macrophage markers and TNF$\alpha$ genes in the tissue, as well as increased insulin resistance $[70,71]$. Mice that consume a high-fat diet show increased expression of MCP-1 mRNA in visceral WAT, but this expression is suppressed by six weeks of spontaneous running activity (Table 1) [25]. Additionally, other studies where mice both consumed a high-fat diet and underwent treadmill running, MCP-1 mRNA expression, which had increased due to the mice's high-fat diet, was reduced by TR (Table 1) [26]. Moreover, nine weeks of treadmill running has reduced MCP-1 protein levels in rat subcutaneous and visceral WAT (Table 1) [27]. However, there were no changes in expression of mRNA for MCP-1 either in the subcutaneous and visceral WAT of rats that performed four weeks of spontaneous running or in the subcutaneous WAT of obese humans who performed 12 weeks of aerobic exercise (Table 1) [24, 32].

There seems to be consensus that TR diminishes blood levels of MCP-1 (Table 3). The blood concentration of MCP-1 was reduced in rats by nine weeks of treadmill running TR [27]. Studies on human patients with metabolic syndrome [64] and obese individuals [32] have also shown reductions and downward trends in MCP-1 after 12 weeks of TR. A 15week combination of TR and diet therapy also reduced the blood concentration of MCP-1 in obese individuals [33].

3.4. Adiponectin. Adiponectin increases fatty acid oxidation and glucose uptake in skeletal muscle and inhibits gluconeogenesis in the liver $[72,73]$. Adiponectin also inhibits the expression and secretion of TNF- $\alpha$ in macrophages and increases the production of anti-inflammatory cytokines such as interleukin (IL)-10 [74]. Therefore, adiponectin is thought to have anti-inflammatory effects. In accordance with that function, the expression of mRNA for adiponectin is reduced in the WAT of genetically obese mice and obese humans, and both obese individuals and diabetic patients have a lower blood concentration compared with healthy individuals $[75,76]$. Insulin resistance and hypertension are improved when KKAy mice (mouse models of obesity and diabetes) are administered physiological concentrations of adiponectin, and insulin resistance is observed in $\mathrm{KO}$ mice deficient in adiponectin, suggesting that obesity-induced decreases in adiponectin expression in WAT are closely associated with the development of insulin resistance and the onset of diabetes $[72,73]$.

A 15-week combination of TR and diet therapy or 12 weeks of aerobic exercise has shown increases in the expression of mRNA for adiponectin in the subcutaneous WAT of obese individuals (Table 1) $[32,33]$. In studies on rats, nine weeks of treadmill running has increased the mRNA expression in visceral and subcutaneous adipocytes (Table 1) [31]. In at least one study, short periods of consuming a highfat diet increased adiponectin expression in the subcutaneous WAT of rats, and TR by spontaneous running activity suppressed this increase. That study found no effect of TR on adiponectin mRNA expression in visceral WAT (Table 1) [24].

As with leptin, there have been many studies on the effects of TR on the blood levels of adiponectin (Table 4) [32, 33, $38,42,45,50,65-69]$. Although most indicate that there is no change, some studies show that it increases, so there is no consensus on this point. Hulver et al. [69] found that the blood concentration of adiponectin did not change after obese adults performed aerobic exercises such as running at 65-85\% $\dot{\mathrm{VO}}_{2}$ max four times a week over a period of six months. Another study on diabetic men also found no change in the blood concentration of adiponectin after eight weeks of performing aerobic exercise three times a week, even though the amount of visceral fat decreased [38]. Even after elderly obese men and women performed TR for 60 minutes on a treadmill or bicycle ergometer at $80-85 \%$ of their maximum heart rate five times a week for 12 weeks, there was no change in the blood concentration of adiponectin despite the deceases in BMI and body fat [67]. Contrary studies have found that 60 minutes of TR, such as running performed four times a week for four weeks, has led to increases in the blood concentration of adiponectin along with decreases in body fat in diabetics and individuals presenting impaired glucose tolerance [65]. In a similar manner, the blood concentration of adiponectin has been increased along with reduced BMI and body fat mass after seven months of TR such as slope jogging and dumbbells performed four to five times a week in obese young women [45].

3.5. IL-6. IL-6 is a cytokine that has a variety of functions such as regulating hematopoiesis, immune response, and inflammatory response. This cytokine also is known to have anti-inflammatory effects, and may have both proinflammatory and anti-inflammatory properties [77, 78]. Diabetic and obese individuals have high blood concentrations of IL-6, and its mRNA expression is elevated in the subcutaneous adipocytes of individuals presenting insulin resistance. Furthermore, IL-6 acts on adipocytes to inhibit insulin signaling $[79,80]$. 


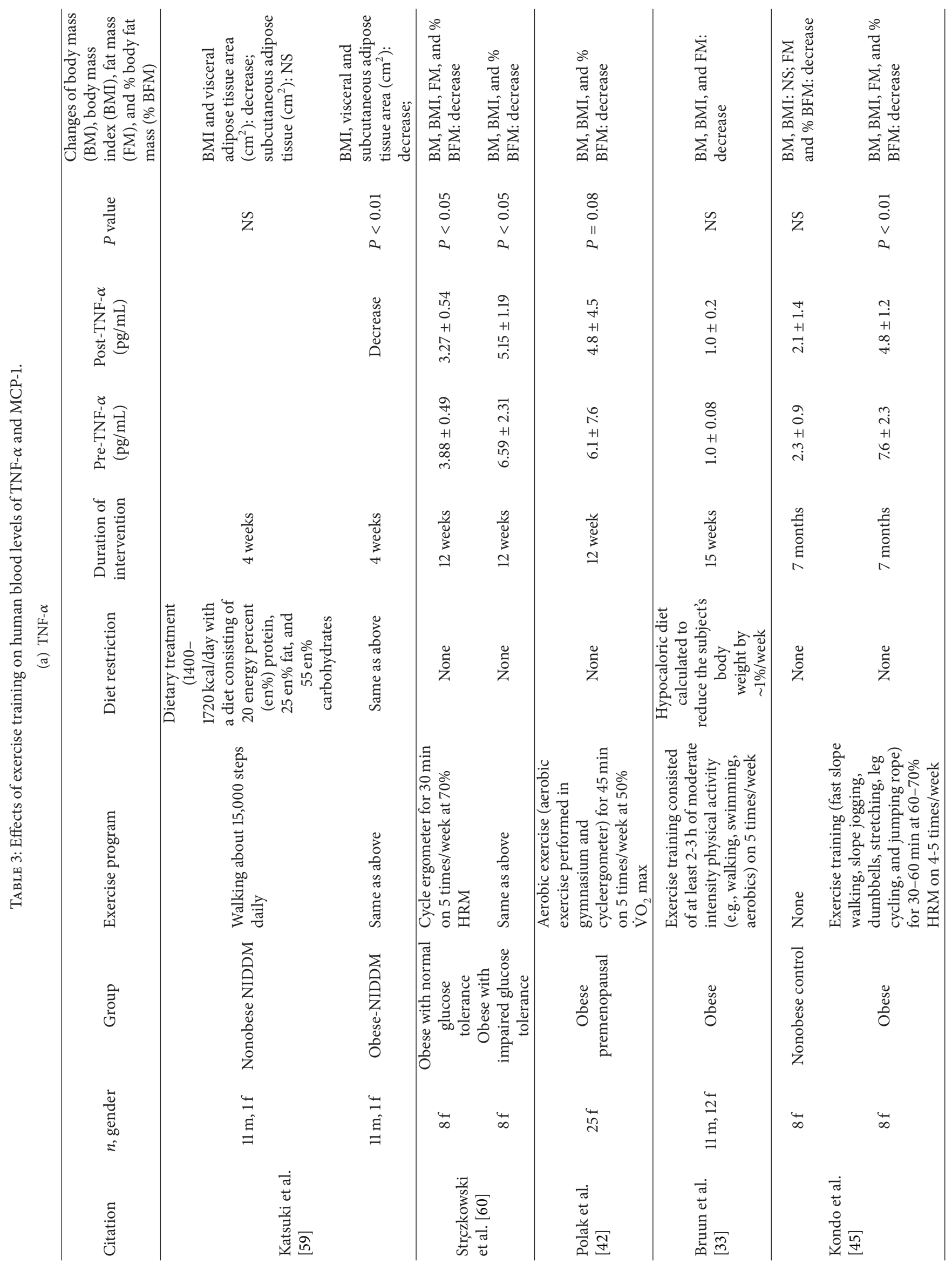




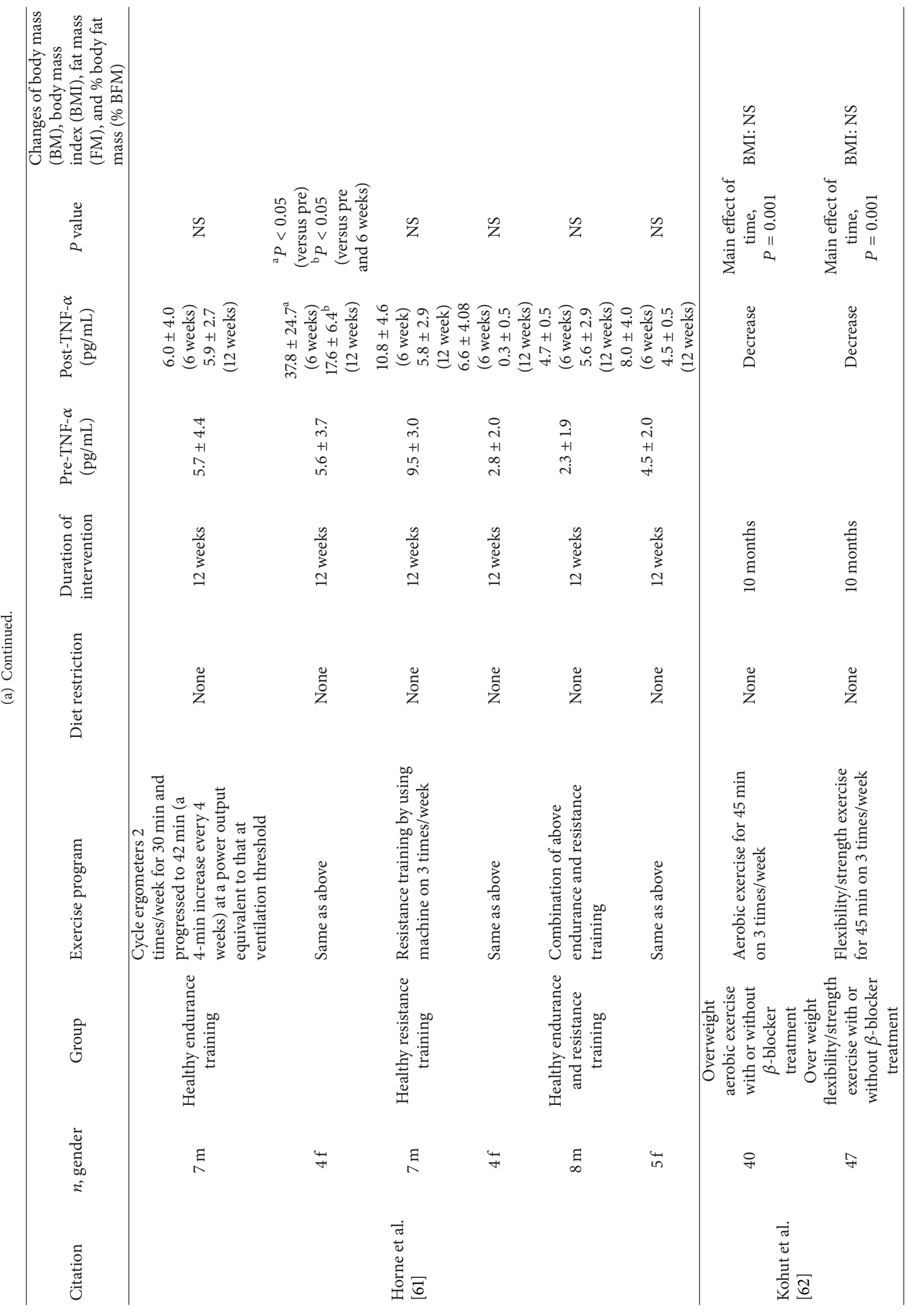




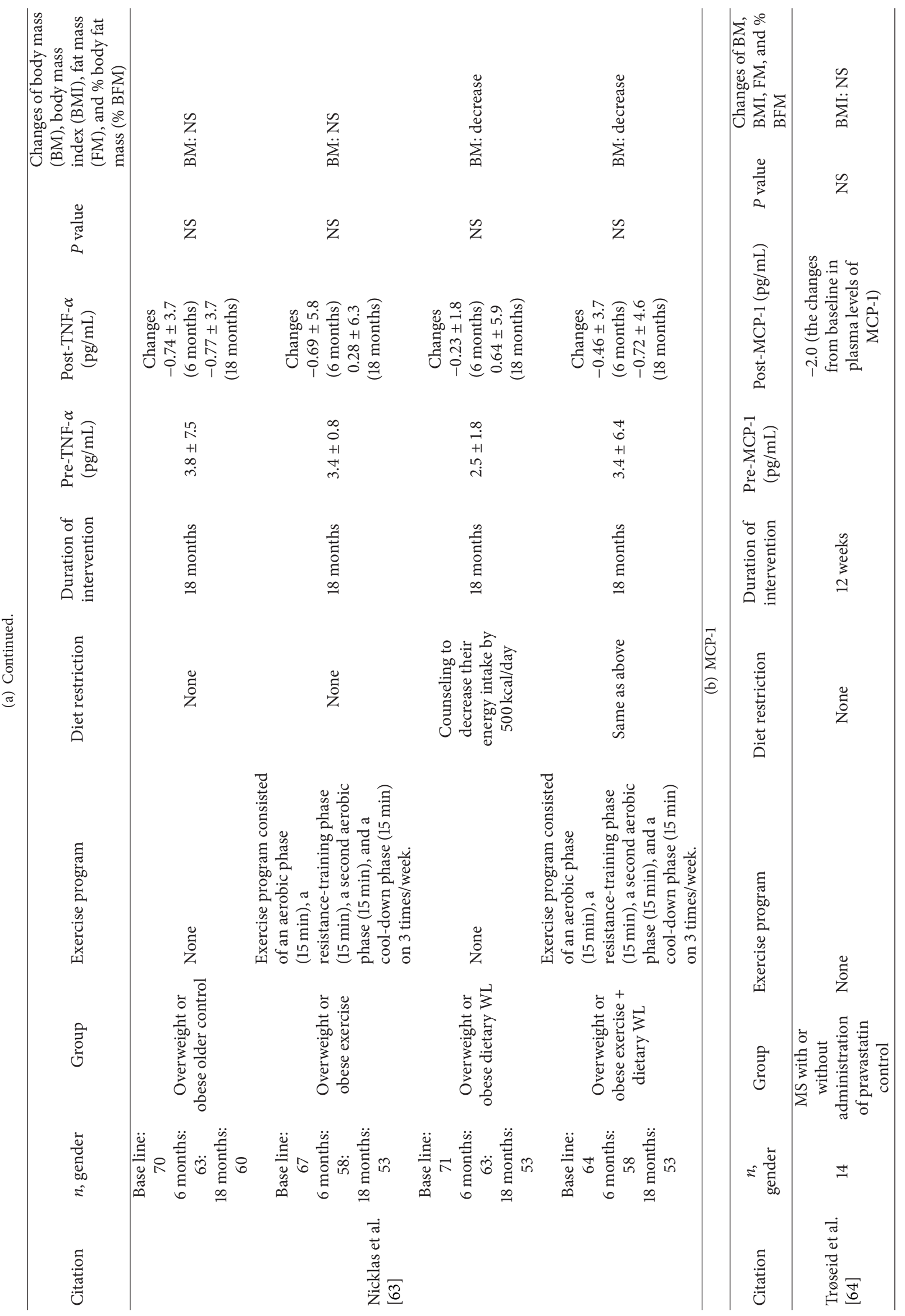




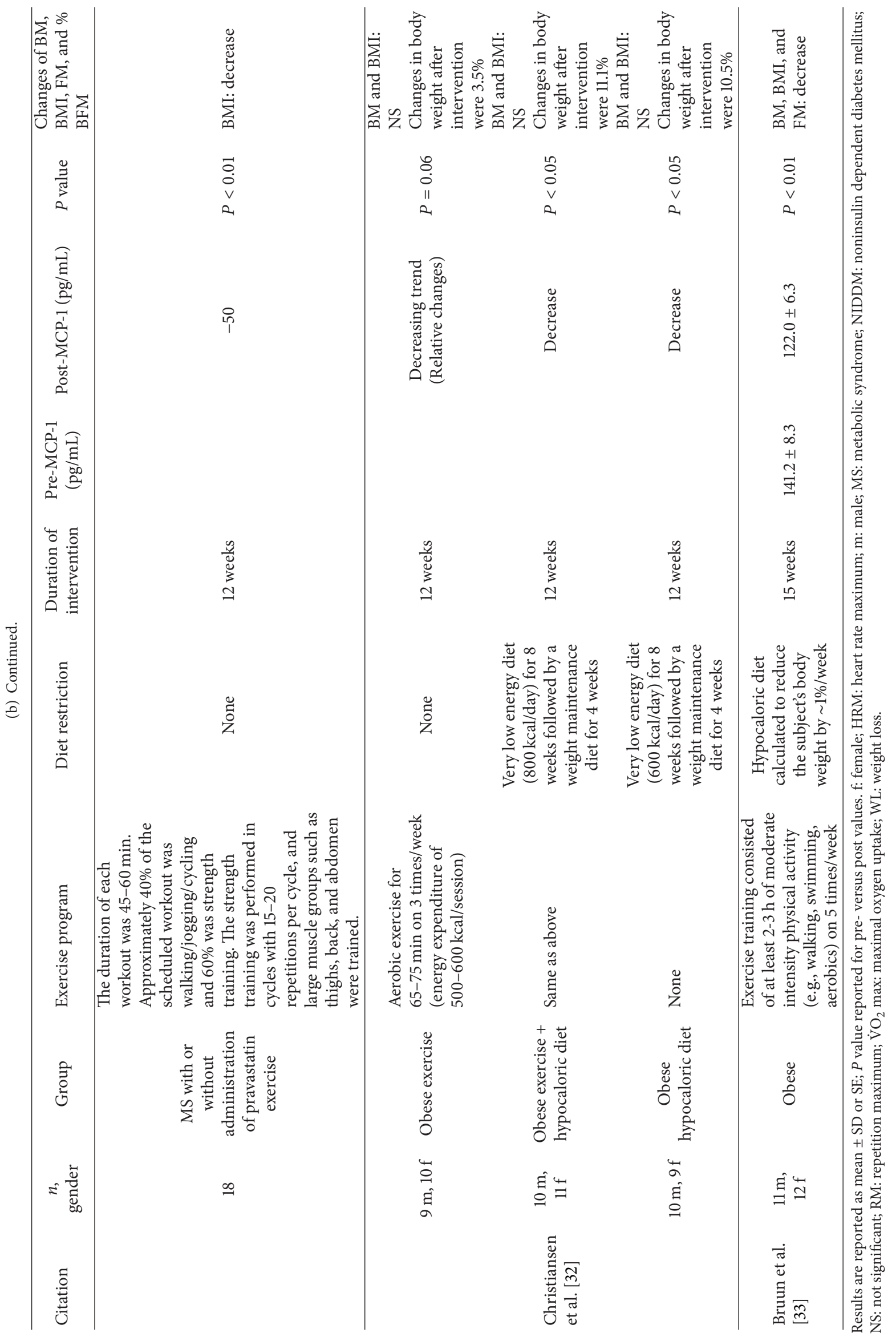




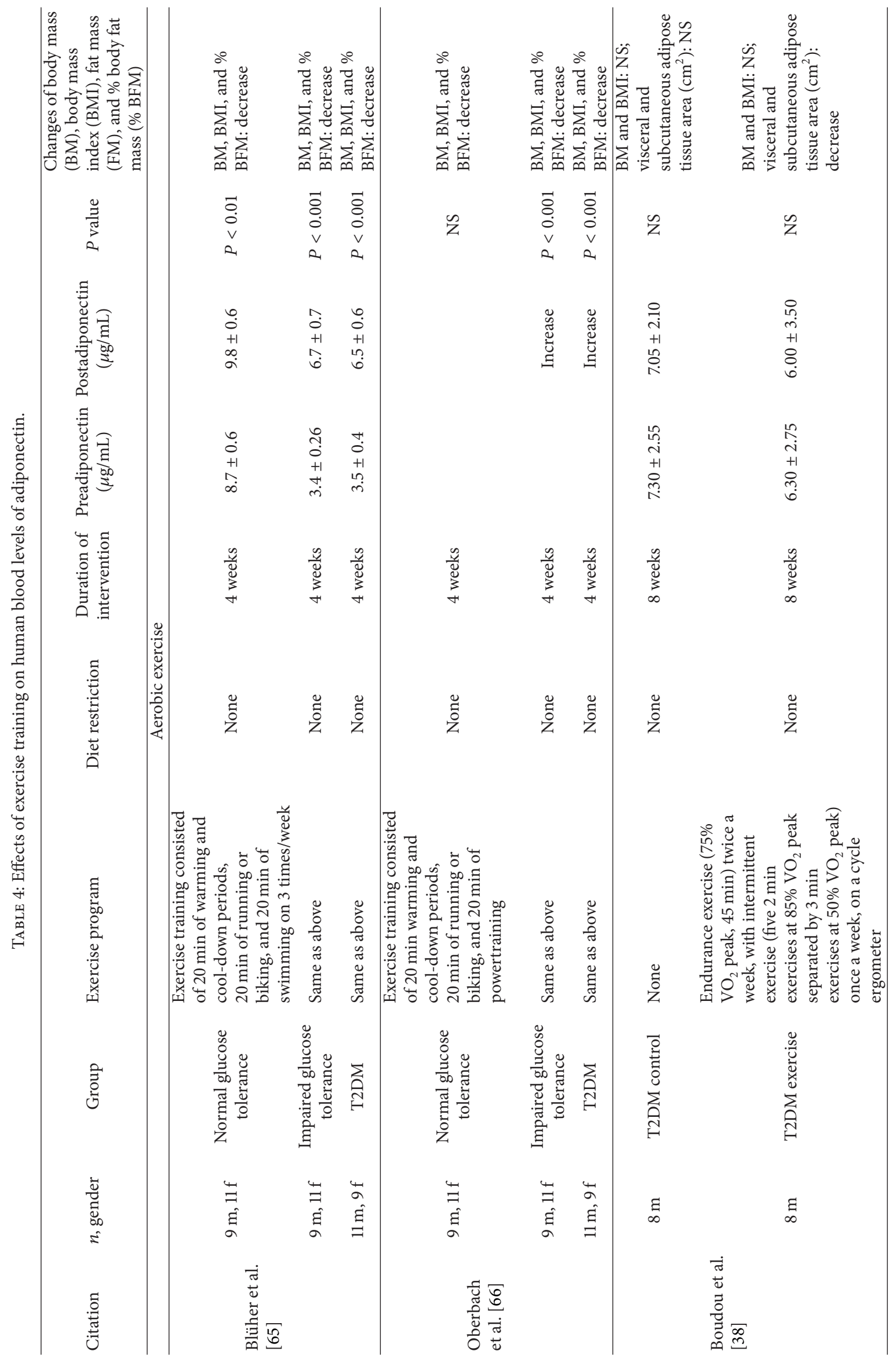




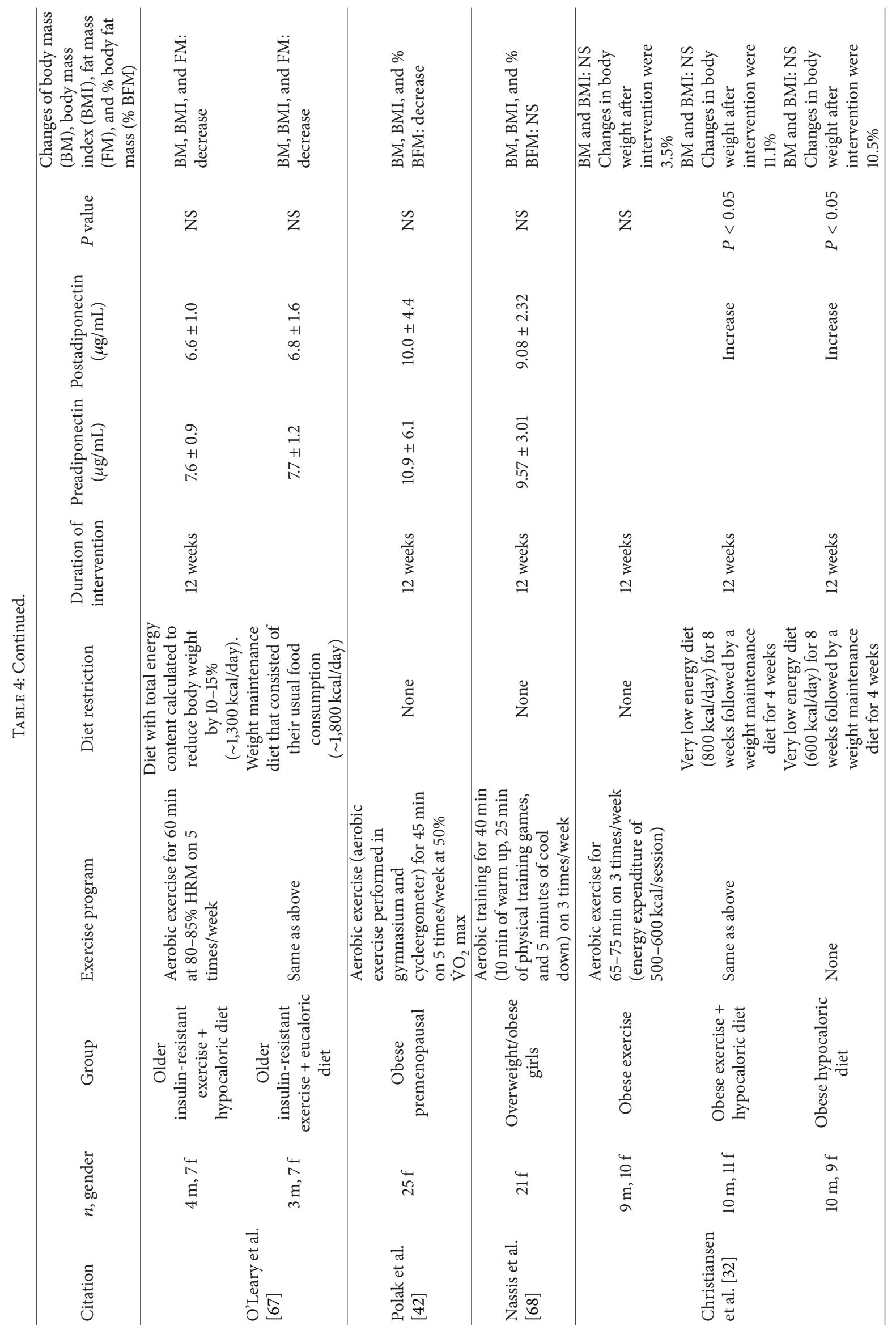




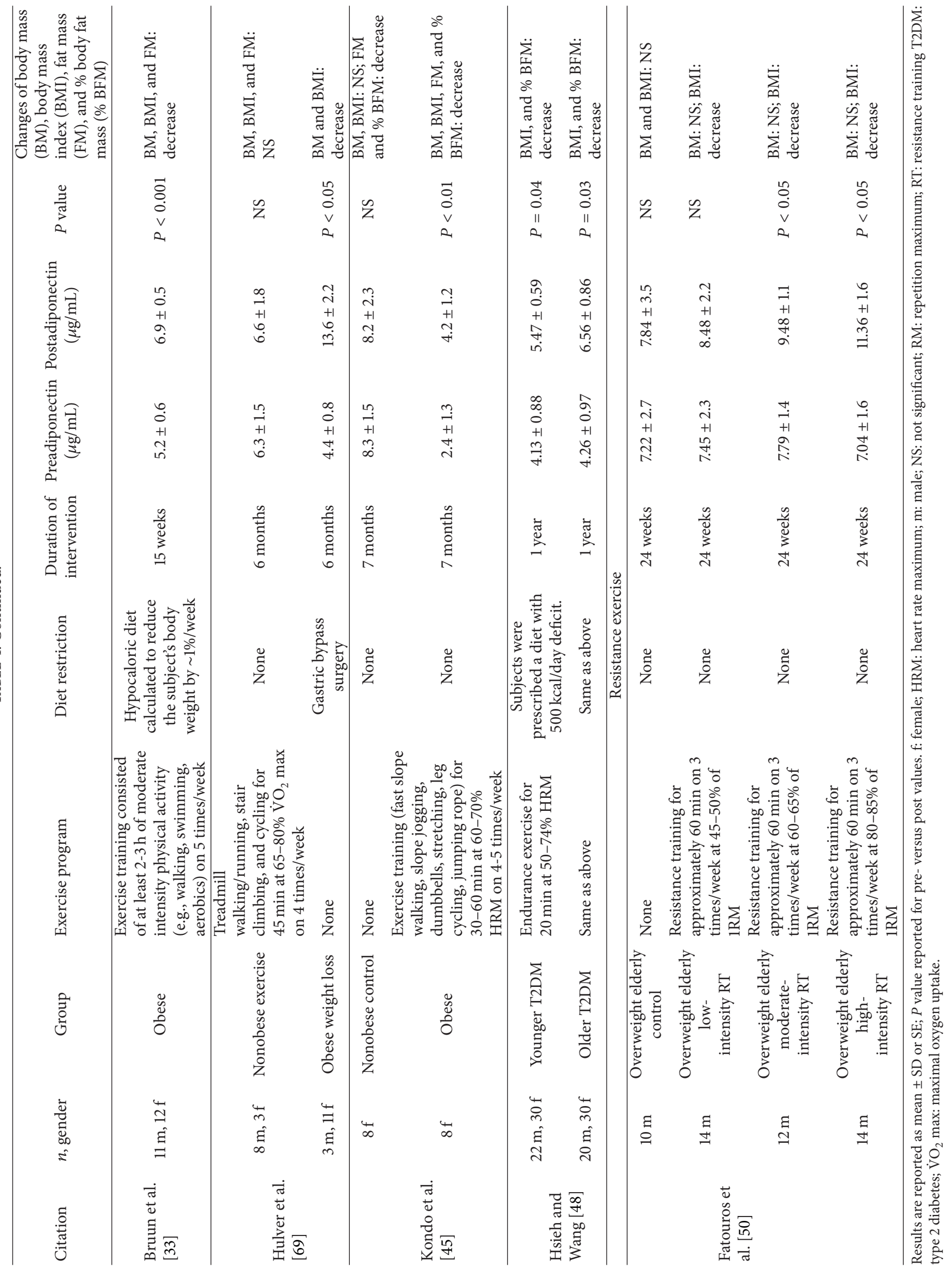


Many studies show that IL-6 levels increase in response to acute exercise; for instance, a single bout of exercise has increased the blood concentration of IL- 6 more than 100 times. However, this increase in blood concentration was not due to increased production by WAT, but rather by increased production in skeletal muscle, an organ that produces IL$6[78,81]$. A 15-week combination of TR and diet therapy reduces the expression of mRNA for IL- 6 in the subcutaneous WAT of obese individuals (Table 1) [33]. However, although some studies show that the blood concentration of IL-6 decreases after TR, other studies have shown no change, so yet again there is no consensus (Table 5) $[33,42,62,63,66$, $68,78]$.

\section{The Relationship between TR-Induced Changes in Adipokine Expression and WAT Mass}

The size of WAT (adipocytes) greatly affects the expression of adipokines. As for leptin, mRNA expression and secretion are positively correlated with the size of adipocytes isolated from rodents and humans [31, 82-84]. Similarly, in isolated adipocytes of humans, secretion of TNF- $\alpha$, MCP-1, and IL-6 is positively correlated with cell size, and after correction for the cell surface, there is still a significant difference between very large and small adipocytes for MCP-1 and IL-6 [83]. Nevertheless, mRNA levels for TNF- $\alpha$ show no significant correlation with mouse adipocyte volume [84]. On the other hand, although the expression of adiponectin is reduced in the WAT of genetically obese mice and obese humans, the mRNA expression and secretion of adiponectin is positively correlated with isolated adipocyte size in rats and humans $[31,75,76,83]$. One of the reasons for this discrepancy is speculated that reduced adiponectin expression in vivo may be the result of inflammatory adipokines, such as TNF- $\alpha$, rather than increases in the size of adipocytes [58]. It is well known that TR reduces WAT mass, and, therefore, the reduction of WAT is thought to be a major factor in the effects of TR on adipokine expression in WAT (Figure 3 ). However, further research is needed regarding other effects of TR. Recently, an interesting study has examined the relationship between TR-induced changes in adipokine expression and WAT mass. Christiansen et al. [32] divided obese subjects into a group that underwent 12 weeks of combined aerobic exercise and diet therapy and a group that underwent diet therapy only, and after adjusting weight loss to approximate amounts, found no difference in changes in either the expression of inflammatory-related adipokines in subcutaneous WAT or in the circulating markers of inflammation; that is, TR seemed to have had no weight-independent effects in that study. On the other hand, when the authors observed a reduced level of leptin mRNA and an elevated mRNA level of adiponectin in rat visceral adipocytes after nine weeks of treadmill running, it suggested that the decrease in leptin mRNA expression depended on a reduction in adipocyte size, and that the increase in adiponectin mRNA was mediated by factor(s) other than adipocyte size [31]. In addition, Oberbach et al. [66] found that actual increases in blood adiponectin after TR were of a higher magnitude than increases in blood adiponectin levels that were predicted according to a regression line drawn from the negative correlation between body fat and the blood concentration of adiponectin.

During exercise, the secretion of catecholamines from the adrenal medulla and sympathetic nerve peripheries breaks down triglycerides within the adipocytes [12]. Several reports have indicated that $\beta$-adrenoceptor agonists affect the expression of some adipokines, such as TNF- $\alpha$ and adiponectin in WAT. Administration of $\beta$-adrenoceptor agonists in lean mice results in upregulation of TNF- $\alpha$ and downregulation of adiponectin in epididymal WAT $[85,86]$. These findings seem to conflict with the beneficial effects of exercise on the disturbance of adipokines. Nevertheless, during exercise, since energy consumption is enhanced, the blockage of lipogenesis by the impaired insulin signaling in WAT might play reasonable roles in the proper execution of exercise. In contrast to lean mice, $\beta$-adrenoceptor agonists recovered the declined mRNA expression of adiponectin and suppressed the overexpressed mRNA level of TNF- $\alpha$ in WAT of KKAy mice [87]. Therefore, in obese and type 2 diabetic patients, it is likely that the secretion of catecholamines during exercise is one of the reasons for the attenuation of dysregulated adipokine expression in WAT (Figure 3 ).

Various possible mechanisms besides decreased WAT mass and secretion of catecholamines have been proposed, including decreased oxidative stress and improvement of hypoxia in WAT (Figure 3). Adipocytes have produced reactive oxygen, and obesity-induced increases in oxidative stress in WAT may be a cause of the dysregulated expression of inflammatory-related adipokines [88]. Studies have shown significantly lower levels of lipid peroxidation in WAT around the epididymis and retroperitoneum of rats that had undergone TR compared with a control group, and elevated protein levels of the antioxidant enzyme manganese superoxide dismutase (Mn-SOD) in the epididymal WAT of TR group rats $[27,28]$. In that study, not only were protein levels of TNF- $\alpha$ and MCP-1 significantly lower in the epididymal WAT of the TR group, compared with those of the control group, the phosphorylation of extracellular signal-regulated kinase, which is activated by reactive oxygen and is important for the expression of MCP-1, also was reduced by TR in WAT around the epididymis and retroperitoneum [27, 89]. TR reduced WAT mass, which likely contributed to decreased oxidative stress in WAT. Nevertheless, because acute exercise elevates oxidative stress in the body [90], the adaptation of WAT against exposure to oxidative stress from exercise, in other words, the expansion of antioxidant systems via increases in $\mathrm{Mn}-\mathrm{SOD}$, could be one reason for decreased levels of proinflammatory adipokines.

Recent evidence that tissue hypoxia is involved in obesityinduced inflammatory changes in WAT has attracted the attention of researchers. In fact, oxygen partial pressure is lower in the WAT of obese animals and humans compared with controls, and results show that this may be related to the inflammatory response in WAT [91, 92]. Although some studies have focused on the impact of TR on blood flow in WAT, results from those studies appear to indicate that when WAT mass decreases due to TR, blood flow in the 







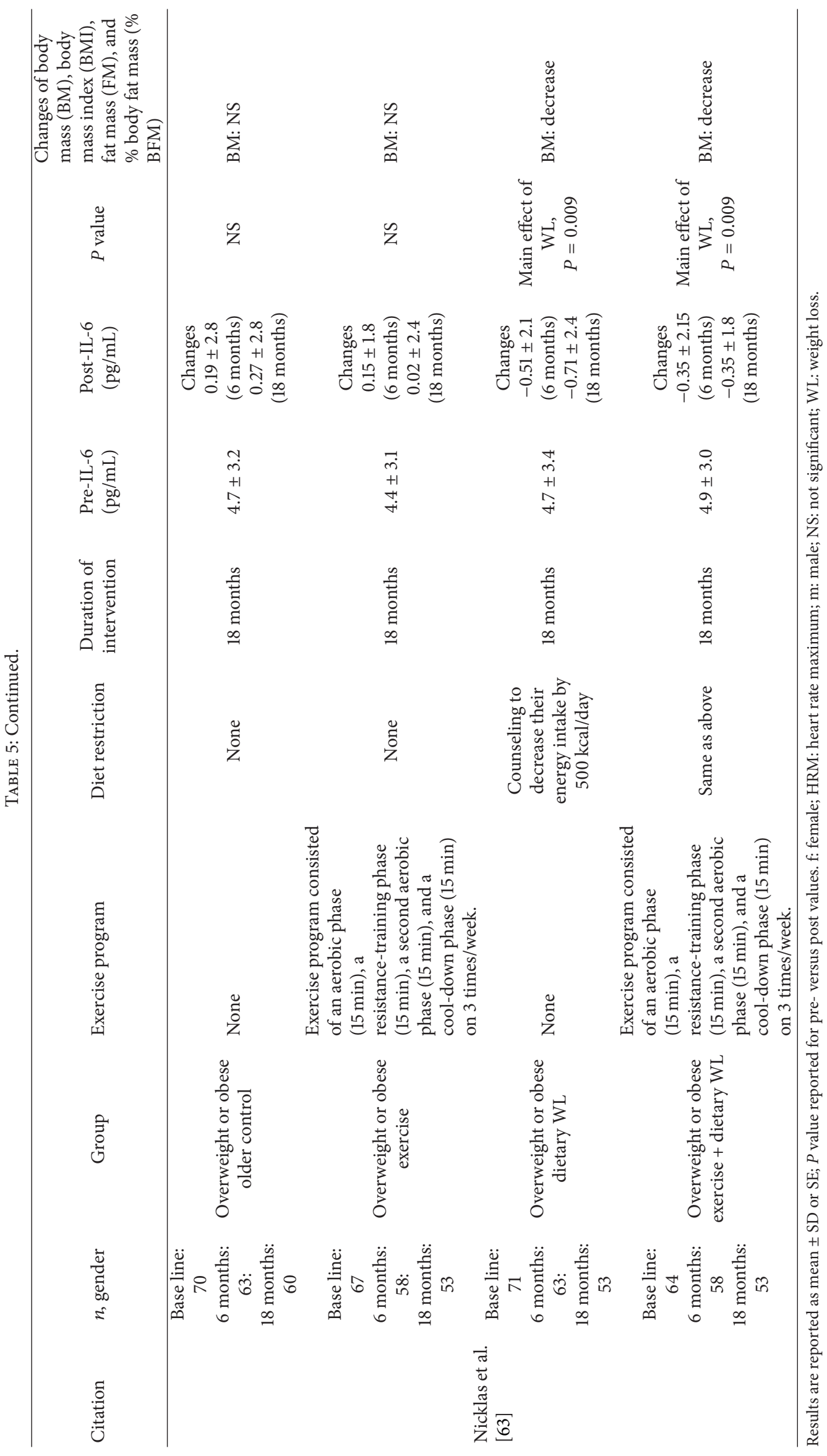




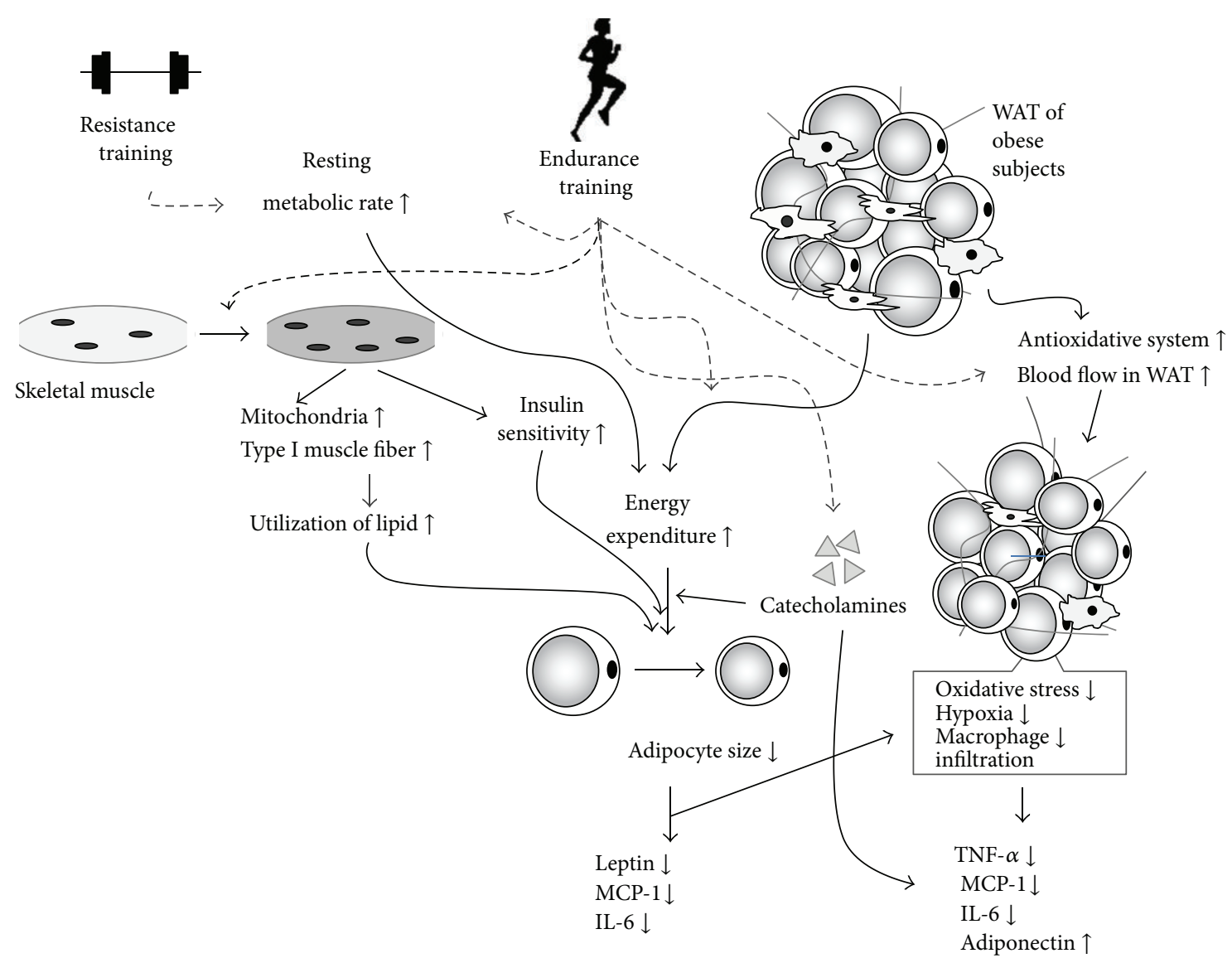

FIGURE 3: Schematic model for the effects of exercise training on expression of adipokines in WAT. During endurance training, type I muscle fibers in skeletal muscle are selectively used for the execution of exercises, and therefore, energy expenditure using lipid increases. Triglycerides within the adipocytes are broken down due to the secretion of catecholamines, and the resultant fatty acids are transported to tissues such as skeletal muscle. When exercise is repeated, adipocyte size is lessened. Decreases in adipocyte size are considered to result in the attenuation of dysregulated expression of adipocyte size-sensitive adipokines, such as leptin and oxidative stress in WAT. Moreover, catecholamine itself seems to correct disarray of adiponectin and TNF- $\alpha$ in WAT of obese subjects. In addition, endurance training might suppress oxidative stress and a hypoxic state of WAT due to an enhanced antioxidative system and increases in blood flow, respectively, which lead to the attenuation of the dysregulated expression of inflammatory-related adipokines involving TNF- $\alpha$ and MCP-1. In skeletal muscle, endurance training produces transition to type I muscle fiber following the increase in mitochondria biogenesis and enhances insulin sensitivity. Consequently, enhanced glucose/lipid metabolism in skeletal muscle decreases adipocyte size. On the other hand, resistance and endurance training enhance resting metabolic rate, which is likely to cause the alteration of adipokine expression following WAT mass reduction due to increased energy expenditure in the resting state.

tissue increases [93]. We found that expression of mRNA for vascular endothelial growth factor and its receptor was elevated in the WAT stromal vascular fraction cells of rats that had engaged in TR, and that the vascular endothelial cell count per unit area had increased [94]. Thus, the increased blood flow to WAT produced by TR eliminated the obesityinduced hypoxia in WAT and could possibly have led to a weakening of the inflammatory changes in WAT.

\section{Can TR That Does Not Alter Body and WAT Mass Alleviate Dysregulated Expression of Adipokines?}

In many of the previous studies that examined the effects of TR on adipokine expression in WAT and on the blood levels of adipokines in human subjects, body mass, BMI, or WAT mass reduction is observed (Tables 1-5). For this reason, it remains unknown whether or not low-intensity TR that does not entail such reduction alters adipokine expression in WAT or blood adipokine levels. As described in the previous chapter, adipokine expression is affected by the size of the WAT (adipocyte). Among adipokines, expression of leptin seems to be especially largely affected by adipocyte size [82-84]. In studies that examined the effect of TR on the blood leptin level in human subjects, results indicated that, in many cases, blood leptin levels do not change without a reduction in body fat; that is, decreased blood leptin levels are thought to be caused by exercise-induced WAT mass reduction (Table 2) [34, 36, 41-45, 47]. In contrast, some studies have reported that the reduced blood leptin level shows beneficial effects of TR without WAT mass reduction. 
For example, studies on adult males and females have shown that only the female subjects exhibit reduced blood leptin levels without body fat loss after undergoing 12 weeks of TR [40]. Similarly, Ishii et al. [37] have demonstrated that TR in type 2 diabetic subjects reduces serum leptin levels independent of changes in body fat mass. On the other hand, increased blood adiponectin level through TR is also accompanied by reductions in body mass, BMI, or WAT mass (Table 4) [33, 45, 48, 65, 66]. Although Hsieh and Wang [48] observed that the blood adiponectin level was significantly elevated in type 2 diabetes patients who performed lowintensity TR (20 min/day, 50-74\% maximum heart rate) and adequate calorie restriction for one year, this particular study showed that body mass reduction seemed to be beneficial for increases in adiponetin. However, other reports indicate that blood adiponectin levels do not change if body mass is decreased [38, 42, 67]. Thus, it is difficult to conclude at this stage whether loss of body and/or WAT mass is indispensable for adiponectin elevation. Moreover, the effects on TR-induced body and WAT mass reduction may differ depending on the type of adipokine. Taken together, these results show that although further examination is necessary, it is conceivable that changes in adipokine expression in WAT and blood adipokine level require TR that is sufficiently intense to reduce body mass or more specifically WAT mass.

\section{Changes in Skeletal Muscle through TR and Its Impact on Expression of Adipokines in WAT}

Skeletal muscle is responsible for physical exercise, and it is the largest tissue in the body. Undernutrition, aging, and sickness cause a decline in skeletal muscle mass (a condition known as muscular atrophy), deteriorating one's exercise capacity $[95,96]$. Moreover, skeletal muscle has a substantial impact on the overall metabolism of the body. For instance, skeletal muscles in patients with obesity and type 2 diabetes have reduced glucose metabolic capacity due to insulin resistance [97], and these observations are considered to be associated with the patients' clinical conditions. Many studies have shown that TR can increase mitochondrial proliferation and boost the expression of a glucose transporter 4 (GLUT4), and can in turn enhance lipid and glucose metabolic capacities [98-100]. Among the molecules involved in exerciseinduced enhancement of glucose/lipid metabolic capacity in skeletal muscle, AMP-activated protein kinase (AMPK) and peroxisome proliferator-activated receptor $-\gamma$ coactivator- $1 \alpha$ (PGC-1 $\alpha$ ) have been gaining a great deal of attention.

AMPK is an enzyme that is activated when ATP is converted to AMP and is a sensor of energy status that maintains cellular energy homeostasis $[101,102]$. Skeletal muscle AMPK is activated by muscle contraction [103], treadmill running [104], and stimulation by its agonist aminoimidazole carboxamide ribonucleotide (AICAR) [105]. Upon activation, AMPK induces the phosphorylation of downstream effectors to elevate glucose uptake. Glucose uptake elevation has been associated with the induction of GLUT4 translocation to the cell membrane [106-108]. AMPK activity has also been reported to be involved in fatty acid uptake through the fatty acid translocase FAT/CD36 and fatty acid oxidation mediated by reduced acetyl-CoA carboxylase enzymatic activity [103, 109]. TR has been shown to enhance both expression and activation of AMPK in skeletal muscle, and chronic AMPK activation in skeletal muscle can increase the number of mitochondria even in the absence of TR, suggesting that TRinduced AMPK activation is strongly involved in the increase in the mitochondria of skeletal muscle [110, 111]. However, a conclusion is yet to be drawn because AMPK KO mice that underwent TR also showed increases in skeletal muscle mitochondria [112].

Transcription coactivator PGC- $1 \alpha$ forms a complex with nuclear receptors and transcription factors to regulate gene transcriptions, or more specifically, expression of genes involved in mitochondrial biosynthesis [113-115]. In fact, mice with PGC-1 $\alpha$ overexpression showed (1) increased number of mitochondria, (2) enhanced expressions of oxidizing enzymes such as cytochrome oxidase in skeletal muscle, and (3) transition to type I muscle fibers [114, 115]. Physical exercise increases PGC- $1 \alpha$ transcription and potentially PGC- $1 \alpha$ activity through posttranslational modifications, and concomitant PGC- $1 \alpha$-mediated gene regulation is suggested to be an underlying mechanism for adaptations in skeletal muscle, when exercise is repeated [115].

Muscle consumes the most energy out of all tissues in the body. Therefore, increases in mitochondria and increased insulin sensitivity in skeletal muscle by endurance TR are thought to dramatically impact the energy consumption of the whole body. Moreover, enhanced glucose/lipid metabolism in skeletal muscle is considered to be indirectly involved in WAT reduction, which results in altered adipokine expression (Figure 3). Additionally, because resting metabolic rate (RMR), which is the largest component of the daily energy budget in most human societies, is reportedly elevated owing to both aerobic and resistance training in human subjects, although some studies have failed to find such an effect [116], enhanced RMR is likely to cause alteration of adipokine expression following WAT mass reduction due to increased energy expenditure in the resting state (Figure 3 ). Nevertheless, the detailed mechanisms and whether mediators, such as myokines, from skeletal muscle act on the existence of WAT remain unknown. On the other hand, it is interesting that evidence is mounting on the new effects of adipokine on skeletal muscle metabolic capacity. Recent observation of $\mathrm{KO}$ mice showed that a lack of adiponectin receptor in their skeletal muscle showed a reduced mitochondrial content, reduced type I muscle fibers, and decreased capacity for exercise, suggesting that adiponectin is involved in mitochondrial biogenesis in skeletal muscles [117]. Furthermore, there is a significant positive correlation between blood adiponectin level and AMPK activity in the lateral great muscles in men [118]. In the future, it is crucial to examine the effect of TR on adipokine expression not only in WAT alone but also in terms of cross-talk between WAT and other tissues involving skeletal muscle. Further investigations are warranted. 


\section{Conclusions}

Although reports on the effects of exercise on adipokine levels in WAT and blood may not always agree due to differences in experimental subjects, exercise intensity, or exercise duration, it is reasonable to believe that there is at least a positive effect. Although TR-induced WAT reduction is one of the key reasons for attenuation of dysregulated expression of adipokines, detailed studies about not only WAT-reducing effects of TR but also other effects, such as antioxidative effects and angiogenic effects, will be necessary to show the usefulness and distinctiveness of TR. Furthermore, it may be significantly beneficial to examine the cross-talk between WAT and other tissues involving skeletal muscle and to what degree WAT contributes to TR-induced changes in blood adipokine levels. Because the importance of exercise as a tool for preventing and improving obesity and lifestylerelated diseases can be expected to grow in the future, further research is desirable.

\section{Conflict of Interests}

The authors have no conflict of interests.

\section{Acknowledgments}

This work was partially supported by Grants-in-Aid for Specific Project Research from the Ministry of Education, Culture, Sport, Science, and Technology of Japan. The authors are also grateful for financial support from the Nakatomi Foundation, Tokyo, Japan.

\section{References}

[1] A. M. Prentice, "The emerging epidemic of obesity in developing countries," International Journal of Epidemiology, vol. 35, no. 1, pp. 93-99, 2006.

[2] F. Sassi, Obesity and the Economics of Prevention: Fit Not Fat, OECD Publishing, Paris, France, 2010.

[3] M. Cecchini, F. Sassi, J. A. Lauer, Y. Y. Lee, V. GuajardoBarron, and D. Chisholm, "Tackling of unhealthy diets, physical inactivity, and obesity: health effects and cost-effectiveness," The Lancet, vol. 376, no. 9754, pp. 1775-1784, 2010.

[4] S. S. Bassuk and J. E. Manson, "Epidemiological evidence for the role of physical activity in reducing risk of type 2 diabetes and cardiovascular disease," Journal of Applied Physiology, vol. 99, no. 3, pp. 1193-1204, 2005.

[5] M. J. Lamonte, S. N. Blair, and T. S. Church, "Physical activity and diabetes prevention," Journal of Applied Physiology, vol. 99, no. 3, pp. 1205-1213, 2005.

[6] S. P. Helmrich, D. R. Ragland, R. W. Leung, and R. S. Paffenbarger Jr., "Physical activity and reduced occurrence of noninsulin-dependent diabetes mellitus," The New England Journal of Medicine, vol. 325, no. 3, pp. 147-152, 1991.

[7] J. E. Manson, D. M. Nathan, A. S. Krolewski, M. J. Stampfer, W. C. Willett, and C. H. Hennekens, "A prospective study of exercise and incidence of diabetes among US male physicians," The Journal of the American Medical Association, vol. 268, no. 1, pp. 63-67, 1992.
[8] J. E. Manson, E. B. Rimm, M. J. Stampfer et al., "Physical activity and incidence of non-insulin-dependent diabetes mellitus in women," The Lancet, vol. 338, no. 8770, pp. 774-778, 1991.

[9] H. Tilg and A. R. Moschen, "Adipocytokines: mediators linking adipose tissue, inflammation and immunity," Nature Reviews Immunology, vol. 6, no. 10, pp. 772-783, 2006.

[10] K. Rabe, M. Lehrke, K. G. Parhofer, and U. C. Broedl, "Adipokines and insulin resistance," Molecular Medicine, vol. 14, no. 11-12, pp. 741-751, 2008.

[11] C. N. Lumeng and A. R. Saltiel, "Inflammatory links between obesity and metabolic disease," The Journal of Clinical Investigation, vol. 121, no. 6, pp. 2111-2117, 2011.

[12] J. F. Horowitz, "Fatty acid mobilization from adipose tissue during exercise," Trends in Endocrinology and Metabolism, vol. 14, no. 8, pp. 386-392, 2003.

[13] Y. Zhang, R. Proenca, M. Maffei, M. Barone, L. Leopold, and J. M. Friedman, "Positional cloning of the mouse obese gene and its human homologue," Nature, vol. 372, no. 6505, pp. 425-432, 1994.

[14] S. P. Weisberg, D. McCann, M. Desai, M. Rosenbaum, R. L. Leibel, and A. W. Ferrante Jr., "Obesity is associated with macrophage accumulation in adipose tissue," The Journal of Clinical Investigation, vol. 112, no. 12, pp. 1796-1808, 2003.

[15] H. Xu, G. T. Barnes, Q. Yang et al., "Chronic inflammation in fat plays a crucial role in the development of obesity-related insulin resistance," The Journal of Clinical Investigation, vol. 112, no. 12, pp. 1821-1830, 2003.

[16] G. Fantuzzi, "Adipose tissue, adipokines, and inflammation," Journal of Allergy and Clinical Immunology, vol. 115, no. 5, pp. 911-919, 2005.

[17] J. L. Halaas, K. S. Gajiwala, M. Maffei et al., "Weight-reducing effects of the plasma protein encoded by the obese gene," Science, vol. 269, no. 5223, pp. 543-546, 1995.

[18] D. L. Morris and L. Rui, "Recent advances in understanding leptin signaling and leptin resistance," American Journal of Physiology: Endocrinology and Metabolism, vol. 297, no. 6, pp. E1247-E1259, 2009.

[19] A. Oswal and G. Yeo, "Leptin and the control of body weight: a review of its diverse central targets, signaling mechanisms, and role in the pathogenesis of obesity," Obesity, vol. 18, no. 2, pp. 221-229, 2010.

[20] R. V. Considine, M. K. Sinha, M. L. Heiman et al., "Serum immunoreactive-leptin concentrations in normal-weight and obese humans," The New England Journal of Medicine, vol. 334, no. 5, pp. 292-295, 1996.

[21] F. Lönnqvist, P. Arner, L. Nordfors, and M. Schalling, "Overexpression of the obese (ob) gene in adipose tissue of human obese subjects," Nature Medicine, vol. 1, no. 9, pp. 950-953, 1995.

[22] M. Mapfei, J. Halaas, E. Ravussin et al., "Leptin levels in human and rodent: measurement of plasma leptin and ob RNA in obese and weight-reduced subjects," Nature Medicine, vol. 1, no. 11, pp. 1155-1161, 1995.

[23] J. J. Zachwieja, S. L. Hendry, S. R. Smith, and R. B. S. Harris, "Voluntary wheel running decreases adipose tissue mass and expression of leptin inRNA in Osborne-Mendel rats," Diabetes, vol. 46, no. 7, pp. 1159-1166, 1997.

[24] K. S. C. Gollisch, J. Brandauer, N. Jessen et al., "Effects of exercise training on subcutaneous and visceral adipose tissue in normal- and high-fat diet-fed rats," American Journal of Physiology: Endocrinology and Metabolism, vol. 297, no. 7, pp. E495-E504, 2009. 
[25] R. L. Bradley, J. Y. Jeon, F.-F. Liu, and E. Maratos-Flier, "Voluntary exercise improves insulin sensitivity and adipose tissue inflammation in diet-induced obese mice," American Journal of Physiology: Endocrinology and Metabolism, vol. 295, no. 3, pp. E586-E594, 2008.

[26] V. J. Vieira, R. J. Valentine, K. R. Wilund, N. Antao, T. Baynard, and J. A. Woods, "Effects of exercise and low-fat diet on adipose tissue inflammation and metabolic complications in obese mice," American Journal of Physiology: Endocrinology and Metabolism, vol. 296, no. 5, pp. E1164-E1171, 2009.

[27] T. Sakurai, T. Izawa, T. Kizaki et al., "Exercise training decreases expression of inflammation-related adipokines through reduction of oxidative stress in rat white adipose tissue," Biochemical and Biophysical Research Communications, vol. 379, no. 2, pp. 605-609, 2009.

[28] T. Sakurai, M. Takei, J. Ogasawara et al., "Exercise training enhances tumor necrosis factor- $\alpha$-induced expressions of antiapoptotic genes without alterations in caspase- 3 activity in rat epididymal adipocytes," Japanese Journal of Physiology, vol. 55, no. 3, pp. 181-189, 2005.

[29] F. S. Lira, J. C. Rosa, A. S. Yamashita, C. H. Koyama, M. L. Batista Jr., and M. Seelaender, "Endurance training induces depotspecific changes in IL-10/TNF- $\alpha$ ratio in rat adipose tissue," Cytokine, vol. 45, no. 2, pp. 80-85, 2009.

[30] M. Nara, T. Kanda, S. Tsukui et al., "Running exercise increases tumor necrosis factor- $\alpha$ secreting from mesenteric fat in insulin-resistant rats," Life Sciences, vol. 65, no. 3, pp. 237-244, 1999.

[31] S. Miyazaki, T. Izawa, J.-E. Ogasawara et al., "Effect of exercise training on adipocyte-size-dependent expression of leptin and adiponectin," Life Sciences, vol. 86, no. 17-18, pp. 691-698, 2010.

[32] T. Christiansen, S. K. Paulsen, J. M. Bruun, S. B. Pedersen, and B. Richelsen, "Exercise training versus diet-induced weight-loss on metabolic risk factors and inflammatory markers in obese subjects: a 12-week randomized intervention study," American Journal of Physiology: Endocrinology and Metabolism, vol. 298, no. 4, pp. E824-E831, 2010.

[33] J. M. Bruun, J. W. Helge, B. Richelsen, and B. Stallknecht, "Diet and exercise reduce low-grade inflammation and macrophage infiltration in adipose tissue but not in skeletal muscle in severely obese subjects," American Journal of Physiology: Endocrinology and Metabolism, vol. 290, no. 5, pp. E961-E967, 2006.

[34] J. R. Berggren, M. W. Hulver, and J. A. Houmard, "Fat as an endocrine organ: influence of exercise," Journal of Applied Physiology, vol. 99, no. 2, pp. 757-764, 2005.

[35] J. A. Houmard, J. H. Cox, P. S. MacLean, and H. A. Barakat, "Effect of short-term exercise training on leptin and insulin action," Metabolism, vol. 49, no. 7, pp. 858-861, 2000.

[36] M. Halle, A. Berg, U. Garwers, D. Grathwohl, W. Knisel, and J. Keul, "Concurrent reductions of serum leptin and lipids during weight loss in obese men with type II diabetes," American Journal of Physiology: Endocrinology and Metabolism, vol. 277, no. 2, pp. E277-E282, 1999.

[37] T. Ishii, T. Yamakita, K. Yamagami et al., "Effect of exercise training on serum leptin levels in type 2 diabetic patients," Metabolism, vol. 50, no. 10, pp. 1136-1140, 2001.

[38] P. Boudou, E. Sobngwi, F. Mauvais-Jarvis, P. Vexiau, and J.-F. Gautier, "Absence of exercise-induced variations in adiponectin levels despite decreased abdominal adiposity and improved insulin sensitivity in type 2 diabetic men," European Journal of Endocrinology, vol. 149, no. 5, pp. 421-424, 2003.
[39] R. R. Kraemer, G. R. Kraemer, E. O. Acevedo et al., "Effects of aerobic exercise an serum leptin levels in obese women," European Journal of Applied Physiology and Occupational Physiology, vol. 80, no. 2, pp. 154-158, 1999.

[40] M. S. Hickey, J. A. Houmard, R. V. Considine et al., "Genderdependent effects of exercise training on serum leptin levels in humans," American Journal of Physiology: Endocrinology and Metabolism, vol. 272, no. 4, pp. E562-E566, 1997.

[41] O. Ozcelik, H. Celik, A. Ayar, S. Serhatlioglu, and H. Kelestimur, "Investigation of the influence of training status on the relationship between the acute exercise and serum leptin levels in obese females," Neuroendocrinology Letters, vol. 25, no. 5, pp. 381-385, 2004.

[42] J. Polak, E. Klimcakova, C. Moro et al., "Effect of aerobic training on plasma levels and subcutaneous abdominal adipose tissue gene expression of adiponectin, leptin, interleukin 6, and tumor necrosis factor $\alpha$ in obese women," Metabolism, vol. 55, no. 10, pp. 1375-1381, 2006.

[43] T. Okazaki, E. Himeno, H. Nanri, H. Ogata, and M. Ikeda, "Effects of mild aerobic exercise and a mild hypocaloric diet on plasma leptin in sedentary women," Clinical and Experimental Pharmacology and Physiology, vol. 26, no. 5-6, pp. 415-420, 1999.

[44] L. Pérusse, G. Collier, J. Gagnon et al., "Acute and chronic effects of exercise on leptin levels in humans," Journal of Applied Physiology, vol. 83, no. 1, pp. 5-10, 1997.

[45] T. Kondo, I. Kobayashi, and M. Murakami, "Effect of exercise on circulating adipokine levels in obese young women," Endocrine Journal, vol. 53, no. 2, pp. 189-195, 2006.

[46] J. E. Reseland, S. A. Anderssen, K. Solvoll et al., "Effect of long-term changes in diet and exercise on plasma leptin concentrations," American Journal of Clinical Nutrition, vol. 73, no. 2, pp. 240-245, 2001.

[47] N. Miyatake, K. Takahashi, J. Wada et al., "Changes in serum leptin concentrations in overweight Japanese men after exercise," Diabetes, Obesity and Metabolism, vol. 6, no. 5, pp. 332-337, 2004.

[48] C. J. Hsieh and P. W. Wang, "Effectiveness of weight loss in the elderly with type 2 diabetes mellitus," Journal of Endocrinological Investigation, vol. 28, no. 11, pp. 973-977, 2005.

[49] A. S. Ryan, R. E. Pratley, D. Elahi, and A. P. Goldberg, "Changes in plasma leptin and insulin action with resistive training in postmenopausal women," International Journal of Obesity, vol. 24, no. 1, pp. 27-32, 2000.

[50] I. G. Fatouros, S. Tournis, D. Leontsini et al., "Leptin and adiponectin responses in overweight inactive elderly following resistance training and detraining are intensity related," Journal of Clinical Endocrinology and Metabolism, vol. 90, no. 11, pp. 5970-5977, 2005.

[51] C. Qi and P. H. Pekala, "Tumor necrosis factor- $\alpha$-induced insulin resistance in adipocytes," Proceedings of the Society for Experimental Biology and Medicine, vol. 223, no. 2, pp. 128-135, 2000.

[52] W. P. Cawthorn and J. K. Sethi, "TNF- $\alpha$ and adipocyte biology," FEBS Letters, vol. 582, no. 1, pp. 117-131, 2008.

[53] G. S. Hotamisligil, P. Arner, J. F. Caro, R. L. Atkinson, and B. M. Spiegelman, "Increased adipose tissue expression of tumor necrosis factor- $\alpha$ in human obesity and insulin resistance," The Journal of Clinical Investigation, vol. 95, no. 5, pp. 2409-2415, 1995.

[54] G. S. Hotamisligil, N. S. Shargill, and B. M. Spiegelman, "Adipose expression of tumor necrosis factor- $\alpha$ : direct role in 
obesity-linked insulin resistance," Science, vol. 259, no. 5091, pp. 87-91, 1993.

[55] P. A. Kern, M. Saghizadeh, J. M. Ong, R. J. Bosch, R. Deem, and R. B. Simsolo, "The expression of tumor necrosis factor in human adipose tissue. Regulation by obesity, weight loss, and relationship to lipoprotein lipase," The Journal of Clinical Investigation, vol. 95, no. 5, pp. 2111-2119, 1995.

[56] G. S. Hotamisligil, A. Budavari, D. Murray, and B. M. Spiegelman, "Reduced tyrosine kinase activity of the insulin receptor in obesity- diabetes. Central role of tumor necrosis factor- $\alpha$," The Journal of Clinical Investigation, vol. 94, no. 4, pp. 1543-1549, 1994.

[57] G. S. Hotamisligil, D. L. Murray, L. N. Choy, and B. M. Spiegelman, "Tumor necrosis factor $\alpha$ inhibits signaling from the insulin receptor," Proceedings of the National Academy of Sciences of the United States of America, vol. 91, no. 11, pp. 48544858, 1994.

[58] N. Maeda, M. Takahashi, T. Funahashi et al., "PPAR $\gamma$ ligands increase expression and plasma concentrations of adiponectin, an adipose-derived protein," Diabetes, vol. 50, no. 9, pp. 20942099, 2001.

[59] A. Katsuki, Y. Sumida, S. Murashima et al., "Serum levels of tumor necrosis factor- $\alpha$ are increased in obese patients with noninsulin-dependent diabetes mellitus," Journal of Clinical Endocrinology and Metabolism, vol. 83, no. 3, pp. 859-862, 1998.

[60] M. Stŗ̧zkowski, I. Kowalska, S. Dzienis-Stŗ̧zkowska et al., "Changes in tumor necrosis factor- $\alpha$ system and insulin sensitivity during an exercise training program in obese women with normal and impaired flucose tolerance," European Journal of Endocrinology, vol. 145, no. 3, pp. 273-280, 2001.

[61] L. Horne, G. Bell, B. Fisher, S. Warren, and A. JanowskaWieczorek, "Interaction between cortisol and tumour necrosis factor with concurrent resistance and endurance training," Clinical Journal of Sport Medicine, vol. 7, no. 4, pp. 247-251, 1997.

[62] M. L. Kohut, D. A. McCann, D. W. Russell et al., "Aerobic exercise, but not flexibility/resistance exercise, reduces serum IL-18, CRP, and IL- 6 independent of $\beta$-blockers, BMI, and psychosocial factors in older adults," Brain, Behavior, and Immunity, vol. 20, no. 3, pp. 201-209, 2006.

[63] B. J. Nicklas, W. Ambrosius, S. P. Messier et al., "Diet-induced weight loss, exercise, and chronic inflammation in older, obese adults: a randomized controlled clinical trial," American Journal of Clinical Nutrition, vol. 79, no. 4, pp. 544-551, 2004.

[64] M. Trøseid, K. T. Lappegård, T. Claud et al., "Exercise reduces plasma levels of the chemokines MCP-1 and IL- 8 in subjects with the metabolic syndrome," European Heart Journal, vol. 25, no. 4, pp. 349-355, 2004.

[65] M. Blüher, J. W. Bullen Jr., J. H. Lee et al., "Circulating adiponectin and expression of adiponectin receptors in human skeletal muscle: associations with metabolic parameters and insulin resistance and regulation by physical training," Journal of Clinical Endocrinology and Metabolism, vol. 91, no. 6, pp. 2310-2316, 2006.

[66] A. Oberbach, A. Tönjes, N. Klöting et al., "Effect of a 4 week physical training program on plasma concentrations of inflammatory markers in patients with abnormal glucose tolerance," European Journal of Endocrinology, vol. 154, no. 4, pp. 577-585, 2006.

[67] V. B. O'Leary, C. M. Marchetti, R. K. Krishnan, B. P. Stetzer, F. Gonzalez, and J. P. Kirwan, "Exercise-induced reversal of insulin resistance in obese elderly is associated with reduced visceral fat," Journal of Applied Physiology, vol. 100, no. 5, pp. 1584-1589, 2006.

[68] G. P. Nassis, K. Papantakou, K. Skenderi et al., "Aerobic exercise training improves insulin sensitivity without changes in body weight, body fat, adiponectin, and inflammatory markers in overweight and obese girls," Metabolism, vol. 54, no. 11, pp. 1472$1479,2005$.

[69] M. W. Hulver, D. Zheng, C. J. Tanner et al., "Adiponectin is not altered with exercise training despite enhanced insulin action," American Journal of Physiology: Endocrinology and Metabolism, vol. 283, no. 4, pp. E861-E865, 2002.

[70] N. Kamei, K. Tobe, R. Suzuki et al., "Overexpression of monocyte chemoattractant protein-1 in adipose tissues causes macrophage recruitment and insulin resistance," The Journal of Biological Chemistry, vol. 281, no. 36, pp. 26602-26614, 2006.

[71] H. Kanda, S. Tateya, Y. Tamori et al., "MCP-1 contributes to macrophage infiltration into adipose tissue, insulin resistance, and hepatic steatosis in obesity," The Journal of Clinical Investigation, vol. 116, no. 6, pp. 1494-1505, 2006.

[72] T. Kadowaki, T. Yamauchi, N. Kubota, K. Hara, K. Ueki, and $\mathrm{K}$. Tobe, "Adiponectin and adiponectin receptors in insulin resistance, diabetes, and the metabolic syndrome," The Journal of Clinical Investigation, vol. 116, no. 7, pp. 1784-1792, 2006.

[73] T. Kadowaki and T. Yamauchi, "Adiponectin and adiponectin receptors," Endocrine Reviews, vol. 26, no. 3, pp. 439-451, 2005.

[74] A. M. Wolf, D. Wolf, H. Rumpold, B. Enrich, and H. Tilg, "Adiponectin induces the anti-inflammatory cytokines IL-10 and IL-1RA in human leukocytes," Biochemical and Biophysical Research Communications, vol. 323, no. 2, pp. 630-635, 2004.

[75] E. Hu, P. Liang, and B. M. Spiegelman, "AdipoQ is a novel adipose-specific gene dysregulated in obesity," The Journal of Biological Chemistry, vol. 271, no. 18, pp. 10697-10703, 1996.

[76] Y. Arita, S. Kihara, N. Ouchi et al., "Paradoxical decrease of an adipose-specific protein, adiponectin, in obesity," Biochemical and Biophysical Research Communications, vol. 257, no. 1, pp. 79-83, 1999.

[77] T. Kishimoto, "Interleukin-6: from basic science to medicine40 years in immunology," Annual Review of Immunology, vol. 23, pp. 1-21, 2005.

[78] A. M. W. Petersen and B. K. Pedersen, "The anti-inflammatory effect of exercise," Journal of Applied Physiology, vol. 98, no. 4, pp. 1154-1162, 2005.

[79] J. R. Berggren, M. W. Hulver, and J. A. Houmard, "Fat as an endocrine organ: influence of exercise," Journal of Applied Physiology, vol. 99, no. 2, pp. 757-764, 2005.

[80] K. Eder, N. Baffy, A. Falus, and A. K. Fulop, "The major inflammatory mediator interleukin-6 and obesity," Inflammation Research, vol. 58, no. 11, pp. 727-736, 2009.

[81] C. P. Fischer, "Interleukin-6 in acute exercise and training: what is the biological relevance?” Exercise Immunology Review, vol. 12, pp. 6-33, 2006.

[82] K.-Y. Guo, P. Halo, R. L. Leibel, and Y. Zhang, "Effects of obesity on the relationship of leptin mRNA expression and adipocyte size in anatomically distinct fat depots in mice," American Journal of Physiology: Regulatory Integrative and Comparative Physiology, vol. 287, no. 1, pp. R112-R119, 2004.

[83] T. Skurk, C. Alberti-Huber, C. Herder, and H. Hauner, "Relationship between adipocyte size and adipokine expression and secretion," Journal of Clinical Endocrinology and Metabolism, vol. 92, no. 3, pp. 1023-1033, 2007. 
[84] Y. Zhang, K.-Y. Guo, P. A. Diaz, M. Heo, and R. L. Leibel, "Determinants of leptin gene expression in fat depots of lean mice," American Journal of Physiology: Regulatory Integrative and Comparative Physiology, vol. 282, no. 1, pp. R226-R234, 2002.

[85] M.-L. Delporte, T. Funahashi, M. Takahashi, Y. Matsuzawa, and S. M. Brichard, "Pre- and post-translational negative effect of $\beta$ adrenoceptor agonists on adiponectin secretion: in vitro and in vivo studies," Biochemical Journal, vol. 367, no. 3, pp. 677-685, 2002.

[86] L. Fu, K. Isobe, Q. Zeng, K. Suzukawa, K. Takekoshi, and Y. Kawakami, " $\beta$-adrenoceptor agonists downregulate adiponectin, but upregulate adiponectin receptor 2 and tumor necrosis factor- $\alpha$ expression in adipocytes," European Journal of Pharmacology, vol. 569, no. 1-2, pp. 155-162, 2007.

[87] L. Fu, K. Isobe, Q. Zeng, K. Suzukawa, K. Takekoshi, and Y. Kawakami, "The effects of $\beta 3$-adrenoceptor agonist CL-316,243 on adiponectin, adiponectin receptors and tumor necrosis factor- $\alpha$ expressions in adipose tissues of obese diabetic KKAy mice," European Journal of Pharmacology, vol. 584, no. 1, pp. 202-206, 2008.

[88] S. Furukawa, T. Fujita, M. Shimabukuro et al., "Increased oxidative stress in obesity and its impact on metabolic syndrome," The Journal of Clinical Investigation, vol. 114, no. 12, pp. 1752-1761, 2004.

[89] A. Ito, T. Suganami, Y. Miyamoto et al., "Role of MAPK phosphatase-1 in the induction of monocyte chemoattractant protein-1 during the course of adipocyte hypertrophy," The Journal of Biological Chemistry, vol. 282, no. 35, pp. 2544525452, 2007.

[90] C. E. Cooper, N. B. Vollaard, T. Choueiri, and M. T. Wilson, "Exercise, free radicals and oxidative stress," Biochemical Society Transactions, vol. 30, no. 2, pp. 280-285, 2002.

[91] N. Hosogai, A. Fukuhara, K. Oshima et al., "Adipose tissue hypoxia in obesity and its impact on adipocytokine dysregulation," Diabetes, vol. 56, no. 4, pp. 901-911, 2007.

[92] J. Ye, Z. Gao, J. Yin, and Q. He, "Hypoxia is a potential risk factor for chronic inflammation and adiponectin reduction in adipose tissue of ob/ob and dietary obese mice," American Journal of Physiology: Endocrinology and Metabolism, vol. 293, no. 4, pp. E1118-E1128, 2007.

[93] B. Stallknecht, "Influence of physical training on adipose tissue metabolism - with special focus on effects of insulin and epinephrine," Danish Medical Bulletin, vol. 51, no. 1, pp. 1-33, 2004.

[94] D. Hatano, J. Ogasawara, S. Endoh et al., "Effect of exercise training on the density of endothelial cells in the white adipose tissue of rats," Scandinavian Journal of Medicine and Science in Sports, vol. 21, no. 6, pp. e115-e121, 2011.

[95] K. L. English and D. Paddon-Jones, "Protecting muscle mass and function in older adults during bed rest," Current Opinion in Clinical Nutrition and Metabolic Care, vol. 13, no. 1, pp. 34-39, 2010.

[96] B, T. Wall, and L. J. van Loon, "Nutritional strategies to attenuate muscle disuse atrophy," Nutrition Reviews, vol. 71, no. 4, pp. 195208, 2013.

[97] V. T. Samuel and G. I. Shulman, "Mechanisms for insulin resistance: common threads and missing links," Cell, vol. 148, no. 5, pp. 852-871, 2012.

[98] Z. Yan, M. Okutsu, Y. N. Akhtar, and V. A. Lira, "Regulation of exercise-induced fiber type transformation, mitochondrial biogenesis, and angiogenesis in skeletal muscle," Journal of Applied Physiology, vol. 110, no. 1, pp. 264-274, 2011.

[99] J. O. Holloszy, "Exercise-induced increase in muscle insulin sensitivity," Journal of Applied Physiology, vol. 99, no. 1, pp. 338$343,2005$.

[100] E. O. Ojuka, V. Goyaram, and J. A. Smith, "The role of CaMKII in regulating GLUT4 expression in skeletal muscle," American Journal of Physiology: Endocrinology and Metabolism, vol. 303, no. 3, pp. E322-E331, 2012.

[101] D. G. Hardie, "AMP-activated protein kinase-an energy sensor that regulates all aspects of cell function," Genes and Development, vol. 25, no. 18, pp. 1895-1908, 2011.

[102] D. G. Hardie, "AMPK: a key regulator of energy balance in the single cell and the whole organism," International Journal of Obesity, vol. 32, no. 4, pp. S7-S12, 2008.

[103] D. Vavvas, A. Apazidis, A. K. Saha et al., "Contraction-induced changes in acetyl-CoA carboxylase and 5'-AMP- activated kinase in skeletal muscle," The Journal of Biological Chemistry, vol. 272, no. 20, pp. 13255-13261, 1997.

[104] W. W. Winder and D. G. Hardie, "Inactivation of acetyl-CoA carboxylase and activation of AMP-activated protein kinase in muscle during exercise," American Journal of Physiology: Endocrinology and Metabolism, vol. 270, no. 2, pp. E299-E304, 1996.

[105] G. F. Merrill, E. J. Kurth, D. G. Hardie, and W. W. Winder, "AICA riboside increases AMP-activated protein kinase, fatty acid oxidation, and glucose uptake in rat muscle," American Journal of Physiology: Endocrinology and Metabolism, vol. 273, no. 6, pp. E1107-E1112, 1997.

[106] T. Hayashi, M. F. Hirshman, E. J. Kurth, W. W. Winder, and L. J. Goodyear, "Evidence for 5'AMP-activated protein kinase mediation of the effect of muscle contraction on glucose transport," Diabetes, vol. 47, no. 8, pp. 1369-1373, 1998.

[107] E. J. Kurth-Kraczek, M. F. Hirshman, L. J. Goodyear, and W. W. Winder, “5' AMP-activated protein kinase activation causes GLUT4 translocation in skeletal muscle," Diabetes, vol. 48, no. 8, pp. 1667-1671, 1999.

[108] H. M. O’Neill, "AMPK and exercise: glucose uptake and insulin sensitivity," Diabetes \& Metabolism Journal, vol. 37, no. 1, pp. 121, 2013.

[109] A. Bonen, X.-X. Han, D. D. J. Habets, M. Febbraio, J. F. C. Glatz, and J. J. F. P. Luiken, "A null mutation in skeletal muscle FAT/CD36 reveals its essential role in insulin- and AICAR-stimulated fatty acid metabolism," American Journal of Physiology: Endocrinology and Metabolism, vol. 292, no. 6, pp. E1740-E1749, 2007.

[110] R. Bergeron, J. M. Ren, K. S. Cadman et al., "Chronic activation of AMP kinase results in NRF-1 activation and mitochondrial biogenesis," American Journal of Physiology: Endocrinology and Metabolism, vol. 281, no. 6, pp. E1340-E1346, 2001.

[111] W. W. Winder, B. F. Holmes, D. S. Rubink, E. B. Jensen, M. Chen, and J. O. Holloszy, "Activation of AMP-activated protein kinase increases mitochondrial enzymes in skeletal muscle," Journal of Applied Physiology, vol. 88, no. 6, pp. 2219-2226, 2000.

[112] S. B. Jørgensen, J. F. P. Wojtaszewski, B. Viollet et al., "Effects of $\alpha$-AMPK knockout on exercise-induced gene activation in mouse skeletal muscle," FASEB Journal, vol. 19, no. 9, pp. 11461148, 2005.

[113] P. Puigserver and B. M. Spiegelman, "Peroxisome proliferatoractivated receptor $\gamma$ coactivator $1 \alpha$ (PGC- $1 \alpha)$ : transcriptional coactivator and metabolic regulator," Endocrine Reviews, vol. 24, no. 1, pp. 78-90, 2003. 
[114] H. Liang and W. F. Ward, "PGC-1 $\alpha$ : a key regulator of energy metabolism," American Journal of Physiology: Advances in Physiology Education, vol. 30, no. 4, pp. 145-151, 2006.

[115] J. Olesen, K. Kiilerich, and H. Pilegaard, "PGC- $1 \alpha$-mediated adaptations in skeletal muscle," Pflügers Archiv, vol. 460, no. 1, pp. 153-162, 2010.

[116] J. R. Speakman and C. Selman, "Physical activity and resting metabolic rate," Proceedings of the Nutrition Society, vol. 62, no. 3, pp. 621-634, 2003.

[117] M. Iwabu, T. Yamauchi, M. Okada-Iwabu et al., "Adiponectin and AdipoR1 regulate PGC- $1 \alpha$ and mitochondria by $\mathrm{Ca}^{2+}$ and AMPK/SIRT1," Nature, vol. 464, no. 7293, pp. 1313-1319, 2010.

[118] L. D. Høeg, K. A. Sjøberg, A. M. Lundsgaard et al., "Adiponectin concentration is associated with muscle insulin sensitivity, AMPK phosphorylation, and ceramide content in skeletal muscles of men but not women," Journal of Applied Physiology, vol. 114, no. 5, pp. 592-601, 2013. 


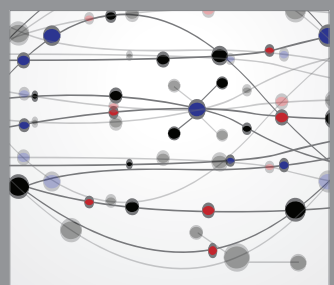

The Scientific World Journal
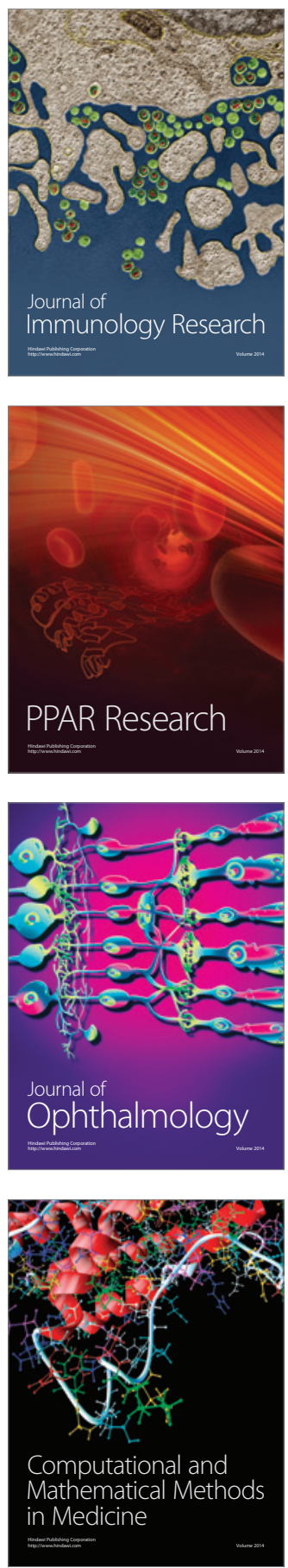



Gastroenterology

Research and Practice
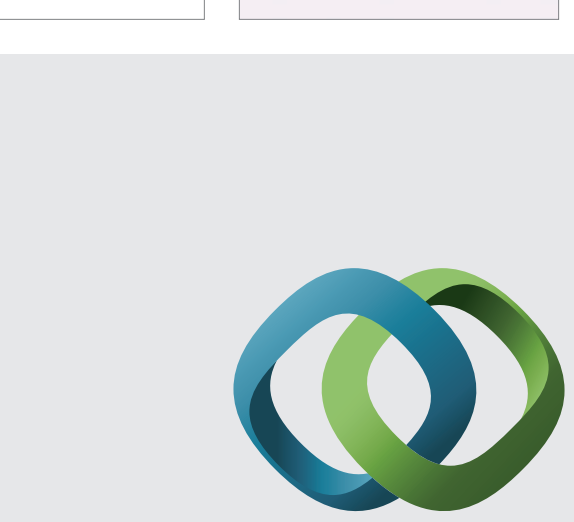

\section{Hindawi}

Submit your manuscripts at

http://www.hindawi.com
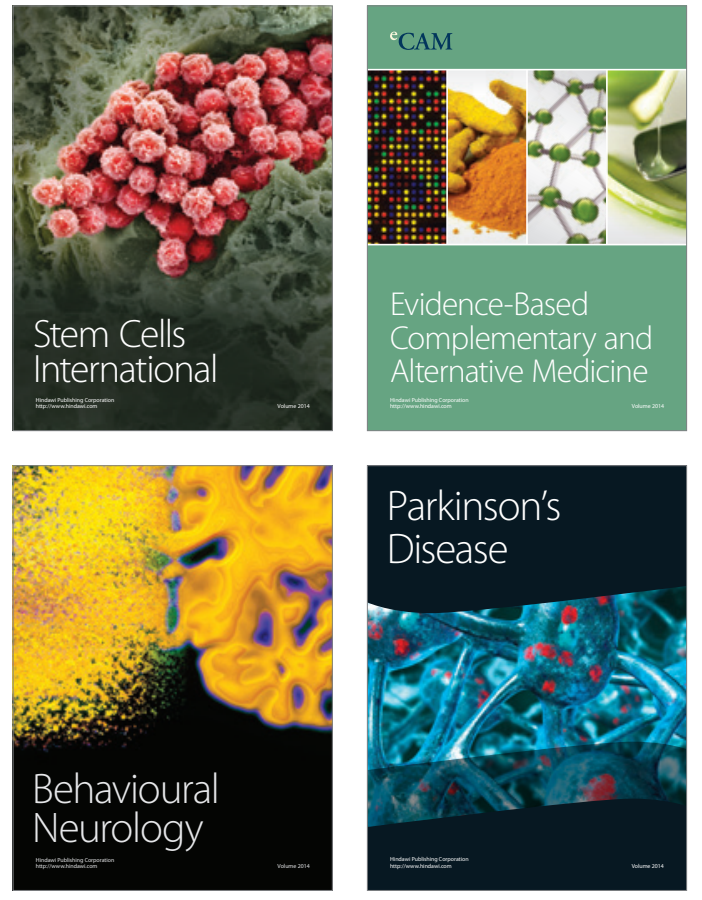
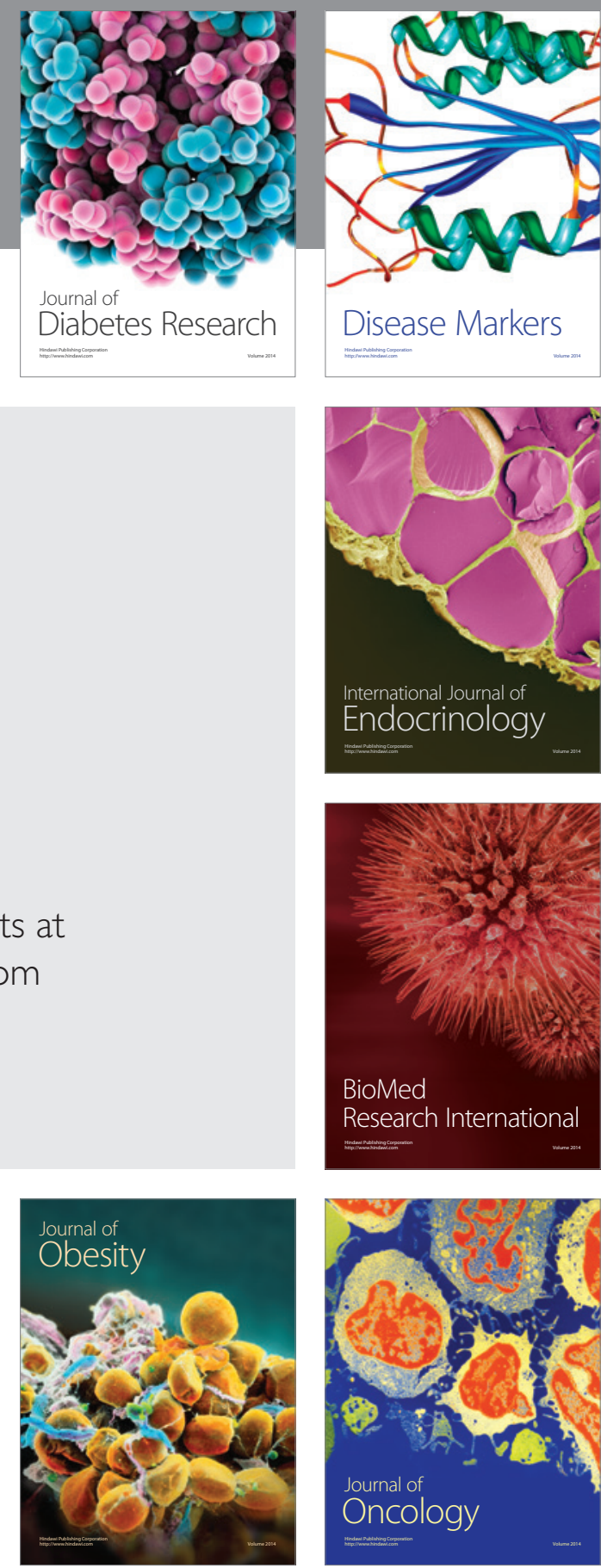

Disease Markers
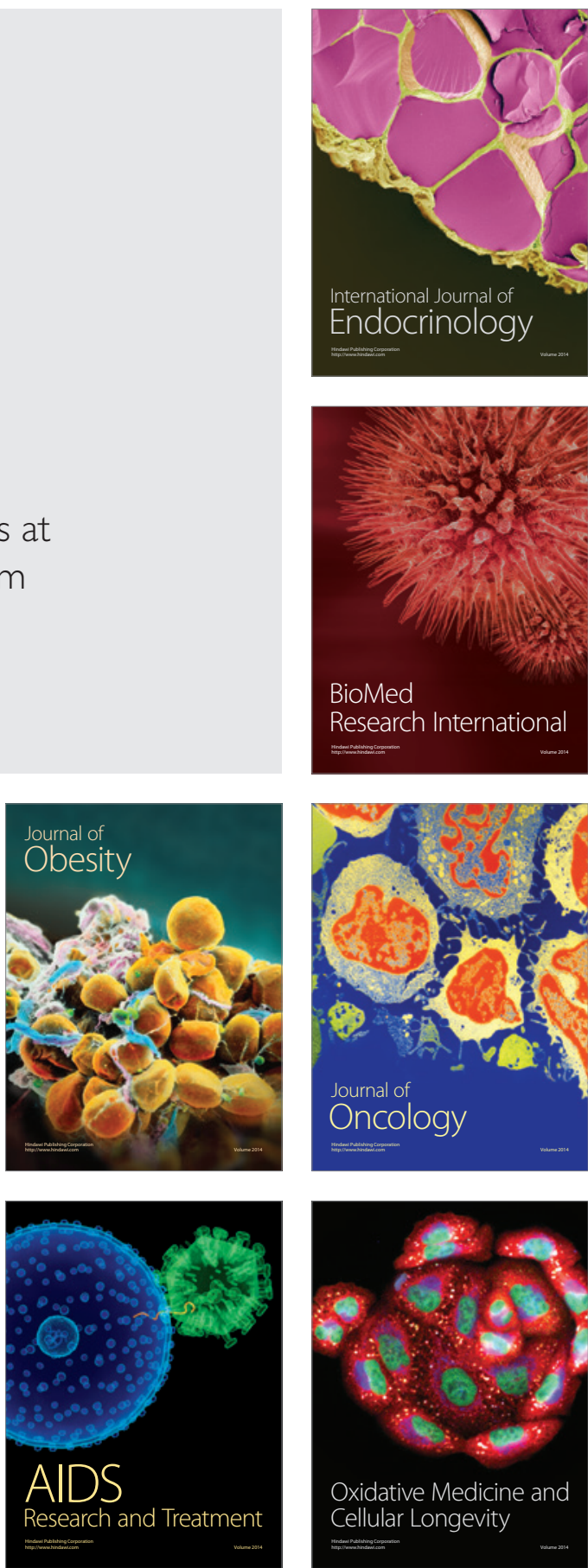